\title{
VARIABILITY OF SILICA FUME CONCRETE AND ITS EFFECT ON SEISMIC SAFETY OF REINFORCED CONCRETE BUILDINGS
}

\author{
${ }^{1}$ Assistant Professor, Department of Civil Engineering, KIIT University, Bhubaneswar, India. Email: \\ sahoo.kirti@gmail.com. \\ ${ }^{2 *} \mathrm{Ph}$. D. Scholar at Department of Civil and Environmental Engineering, University of Strathclyde, \\ Glasgow, UK, Email: prateek.dhir@strath.ac.uk (corresponding author) \\ ${ }^{3}$ M. Tech. Scholar at Department of Civil Engineering, National Institute of Technology, Rourkela, India, \\ 769008, India. Email: prraviteja04@gmail.com.
}

${ }^{4}$ Associate Professor, National Institute of Technology, Rourkela, India, 769008, Email: sarkar.pradip@gmail.com.

${ }^{5}$ Assistant Professor, National Institute of Technology, Rourkela, India, 769008, Email: robin.davisp@gmail.com.

\section{ABSTRACT}

Design of structures made using Silica Fume (SF) concrete to an acceptable level of safety requires the probabilistic evaluation of its mechanical properties. An extensive experimental program was carried out on compressive strength, flexural strength and tensile splitting strength of SF concrete. Seven concrete mixes with different proportions of SF were designed to produce 490 concrete samples. The probabilistic models to describe the variability of the mechanical properties of SF concrete were proposed. Two parameter probability models such as Weibull, normal, lognormal and gamma distribution were considered for the representation of variability. The probability distribution models were selected based on the three goodness-of-fit tests such as the Kolmogorov-Sminrov (KS), Chi-square (CS) and log-likelihood (LK) tests. The results obtained from the models are useful for description of the variability of selected mechanical 
properties of SF incorporated concrete. This study proposed lognormal distribution function as the distribution model that most closely describes the variations of different mechanical properties of SF concrete for a practical point of view. Further, the performance of typically selected buildings using SF concrete was evaluated through fragility curves and reliability indices incorporating the proposed probability distributions and variability of compressive strength property. It was found that $15 \%$ to $25 \%$ of partial replacement of cement with SF may yield better performance of the frames.

Keywords: Variability, silica fume concrete, compressive strength, flexural strength, tensile splitting strength, fragility curve, seismic hazard curve, reliability curve

\section{INTRODUCTION}

Accumulations of industrial waste products create environmental problems and outline the need for their greater utilization in different fields. The construction field utilizes such materials by replacing it partially as a supplementary cementing material in concrete and contributes towards the sustainability. Supplementary materials like fly ash, SF, metakaolin and ground granulated blast furnace slag (Radonjanin et al. 2013) are used due to their pozzolanic activity and among them, SF is found to be highly operative in the design and development of concrete (Siddique 2011). The incorporation of SF concrete in the construction sector is gaining popularity in the recent years, which demands the design and safety assessment of these structures in the future. The structural performance and safety of any kind of structure is dependent on the uncertainty in the properties of materials. But, in reality, this phenomenon is ignored in conventional structural design and analysis. The assumption of the deterministic values of the material properties is less satisfactory and less realistic. Now a days due to advancement in technology, complex structural analyses like probablistic study can be easily performed by considering various uncertainty parameters of the structures and its response against the natural loads such as earthquake, wind etc.

Several studies (Campbell and Tobin 1967, Soroka 1968, Chmielewski and Konapka 1999, Graybeal and Davis 2008) have been performed on the variability of the compressive strength of concrete. The 
variability of compressive strength of concrete is usually represented in literature by a normal distribution if the coefficient of variation does not exceed $15-20 \%$, although slight skewness may be present. However, when the coefficient of variation is high, the skewness is considerable (Campbell and Tobin 1967) and if the quality control is poor (Soroka 1968), a lognormal distribution is more rational to represent the tail areas of distribution than a normal distribution. A recent study (Chen et al. 2013) concludes that the variation in concrete compressive strength should be characterized using various statistical criteria and different distribution functions.

The inherent variability of cement and SF may not be similar in nature as it is a by-product in the carbothermic reduction of high-purity quartz with carbonaceous materials like coal, coke, wood-chips in the production of silicon and ferrosilicon alloys. Therefore, the existing literature on the variability of cement concrete may not be useful to describe the variability of concrete with SF. In the present study, different probability functions along with traditionally used normal and lognormal functions were implemented for the explanation of the variation of diverse mechanical properties of SF concrete obtained experimentally. A best-fitted probability distribution function for mechanical properties of concrete with different amount of SF is developed adopting various statistical tests. Further, the relative seismic vulnerability of buildings made with a specified percentage of SF is studied in comparison with a regular Reinforced Concrete (RC) buildings for a site hazard conditions in a practical load and resistance factor format.

\section{RESEARCH SIGNIFICANCE}

Performance-based analysis requires probabilistic distributions of the constituent materials in the structure. Though the variability in the mechanical properties associated with normal concrete is reported in the literature, however, most of the literature did not reveal about the variability of concrete made with partial replacement of SF. In this research, three important mechanical properties: compressive strength, flexural strength and tensile splitting strength of SF concrete were described through the probability distribution functions. Best fitted probability distribution function is developed by performing numerous 
goodness-of-fit tests. Further, the performance of typically selected buildings using SF incorporated concrete is evaluated through fragility curves and reliability indices incorporating the proposed probability distributions and variability of compressive strength of SF concrete. The development of probability description of the SF concrete and the seismic performance assessment of buildings built with SF incorporated concrete is a new research attempt in this study.

\section{EXPERIMENTATION}

The experimental program consists of seven sets of concrete mixes with partial replacement of SF. Most of the previous studies on SF concrete, consider the partial replacement of cement keeping the total weight of cementitious material, fine and coarse aggregate as constant values. The main purpose of these studies was to evaluate the effect of SF on the behavior of concrete. International codes like Indian Standard, IS10262 (2009) and ACI 234R (96) recommends an extra cement of 10\%, while mineral admixture like silica fume is used as partial replacement of cement. The present study focuses on the variability of mechanical properties SF incorporated concrete and its effect on the seismic performance of SF incorporated (as per the above codes) RC frames. Weight proportions of cement, SF, natural sand, coarse aggregates, water and admixture for all the seven mixes are shown in Table 1 . The cement content in the control mix is found to be about $308 \mathrm{~kg} / \mathrm{m}^{3}$, while the total cementitious content, in the mixtures where the replacement of SF is carried out, is kept constant at about $338 \mathrm{~kg} / \mathrm{m}^{3}(1.10$ times of the cement content of the control mix) as per IS 10262 (2009). As the percentage of SF increase the cement contents in SF concrete mixtures reduces from $322 \mathrm{~kg} / \mathrm{m}^{3}(5 \% \mathrm{SF})$ to $237 \mathrm{~kg} / \mathrm{m}^{3}(30 \% \mathrm{SF}$ ). The doses of SF are $0 \%$ (control mix), 5\%, 10\%, 15\%, 20\%, 25\%, and 30\% of the total cementitious material (Atiş et al. 2005, Poon et al. 2006). Water content is kept constant as $148 \mathrm{~kg} / \mathrm{m}^{3}\left[9.239 \mathrm{lb} / \mathrm{ft}^{3}\right]$, maintaining maximum doses of superplasticizer as $1.3 \%$ of cement weight. Portland Slag Cement having the 28 -day compressive strength of $48 \mathrm{MPa}$ [6.96 ksi] and SF of grade 920-D having a specific surface area of about $19.5 \mathrm{~m}^{2} / \mathrm{kg}$ [95.22 $\mathrm{ft}^{2} / \mathrm{lb}$ ] were used in this study. The chemical and physical properties of cement and SF were analyzed and found to be conforming to the relevant standard (ASTM C989/C989M-14 for cement and ASTM C1240 for SF) 
and shown in Table $2 \& 3$. The specific gravity of cement and SF were found to be 3.01 and 2.26 respectively. Natural river sand conforming to Zone-II of IS 383 (1970) was used as fine aggregate. Specific gravity and water absorption of fine aggregates were obtained as 2.65 and $0.8 \%$, respectively. Crushed angular graded coarse aggregate obtained from a local quarry having a nominal maximum size of $20 \mathrm{~mm}$ [0.78 inches] was used. The specific gravity and the water absorption of the coarse aggregates were 2.75 and $0.6 \%$ respectively.

Test specimens (Cube size: 100mm x 100mm x 100mm, Cylinder size: 100mm x 200mm, Prism size: $100 \mathrm{~mm} \times 100 \mathrm{~mm} \times 500 \mathrm{~mm}$ ) were prepared from each of the seven mixes for compressive strength, tensile splitting strength and flexural strength test. The specimens were casted in a weather condition where the ambient temperature range was about $21^{\circ} \mathrm{C}$ to $45^{\circ} \mathrm{C}$ and humidity range was about $47 \%$ to $63 \%$. The curing was carried out in water filled tank located adjacent to the laboratory for 28 days.

\section{Variability in Mechanical Properties}

All the specimens mentioned in the previous section were tested according to relevant Indian Standards. Individual test results, including the associated mean and standard deviation for compressive strength, flexural strength, and split tensile strength respectively in the Tables 1A to 3A (in the APPENDIX).

The compressive strength of concrete cubes $(7$ mixes $\times 30$ samples each $=210$ total samples $)$ with various SF content is presented in Table 4. The compressive strength of control specimen was found to be varying from 24.18 MPa [3.50 ksi] to $34.60 \mathrm{MPa}$ [5.01 ksi] with a mean and Standard deviation (SD) of 30.27 MPa [4.38 ksi] and 2.17 MPa [0.314 ksi]. Similarly, the minimum, maximum, mean and SD for other concrete specimens having a different percentage of SF is shown in this table. The mean compressive strength of concrete increases with SF content and it reaches maximum value $53.97 \mathrm{MPa}[7.825 \mathrm{ksi}]$ at $20 \%$ SF content. The table also shows that the SD of compressive strength increases with the increase in SF content. This may be attributed to the high inherent variability in the properties of SF. The mean compressive strengths of concrete obtained for each SF dosage are plotted in Fig. 1. 
Flexural strength of concrete prisms $(7$ mixes $\times 20$ samples each $=140$ total samples $)$ with various SF content is presented in Table 4. The flexural strength of control specimen is varying from 5.94 MPa [0.86 ksi] to $6.41 \mathrm{MPa}$ [0.92 ksi] with a mean and SD of $6.32 \mathrm{MPa}$ [0.91 ksi] and $0.33 \mathrm{MPa}$ [0.04 ksi]. Similarly, the minimum, maximum, mean and SD for other concrete specimens having a different percentage of SF is presented in Table 4. The mean flexural strength of concrete increases with SF content and it reaches maximum value $8.35 \mathrm{MPa}$ [1.21 ksi] at $25 \% \mathrm{SF}$ content. It can be seen from this table that the SD values of concrete follow the non-uniform trend with the increase in SF content. The mean flexural strength of concrete obtained for each SF dosage is plotted in Fig. 2.

The tensile splitting strengths of the concrete cylinder $(7$ mixes $\times 20$ samples each $=140$ total samples $)$ with various SF contents are presented in Table 4. The tensile splitting strength of the control specimen varies from 2.21 MPa [0.32 ksi] to $2.96 \mathrm{MPa}$ [0.42 ksi] with a mean and SD of $2.60 \mathrm{MPa}$ [0.37 ksi] and $0.23 \mathrm{MPa}[0.3 \mathrm{ksi}]$ respectively. Similarly, the minimum, maximum, mean and SD for other concrete specimens having a different percentage of SF is shown in Table 4. The mean tensile splitting strength of concrete increases with SF content and it reaches a maximum value of $3.91 \mathrm{MPa}[0.56 \mathrm{ksi}]$ at $20 \% \mathrm{SF}$ replacement. This table shows that the SD of tensile splitting strength increases with the increase in SF content. The mean tensile splitting strengths of concrete obtained for each SF dosage are plotted in Fig. 3.

\section{Development of Variability Models}

Design and safety assessment of structures made of silica fume concrete requires probabilistic models that describe the variability of its mechanical properties. This section focuses on the representation of variability of compressive strength, flexural strength and tensile splitting strength using different probability distribution models. Values of all the mechanical properties obtained experimentally were converted to probability distribution functions using the shape and scale parameters obtained from the sample data (e.g. for normal distribution: shape and scale factor implies the mean and standard deviation values respectively). Certain pre-decided standard probability distribution models selected in the present work are; truncated normal, lognormal, gamma and Weibull distributions. Certain statistical goodness-of- 

Chi-square criterion (CS) at the 5\% significance level were performed. The probability distribution which has minimum values of KS distance and CS value and the maximum value of LK was considered as the best fit. These methods have been successfully used in many past works of literature (Chen et al. 2013, Stone et al. 1986).

The distribution is rejected if the goodness-of-fit test values are below the critical value specified at the $5 \%$ significance level. The values obtained for the rejected distributions were omitted in the presentation of results. The selection criteria for a best-fit distribution is the minimum values of KS distance and CS along with the maximum value of LK. The CS value may not be always reliable (Chen et al. 2013) because it depends on the binning of data into intervals and it is best suitable when large random variables are used. Therefore, the best-fitted distribution was decided from KS distance and LK value even if the CS value is not the minimum.

The estimated parameter values of different distributions for compressive strength, flexural strength and tensile splitting strength are reported in Tables 5, 6, and 7 respectively. The graphical representation of cumulative probability distributions from experiments was compared with assumed distribution functions for all data sets as shown in Figs. 4-6.

\section{Statistical Inference for compressive strength, flexural strength and tensile splitting strength}

The parameters (KS distances, LK and CS values) of the goodness-of-fit tests for the mechanical properties, compressive strength, flexural strength and tensile strength are shown in Table 5-7 respectively. The three criteria (KS, CS and LK) were found to be not in agreement simultaneously to choose a single probability distribution for a variability description of compressive strength. However, there are negligible deviations among the goodness-of-fit test values for all the cases of mix proportions. A single probability distribution was found to satisfy all the test criteria to yield the minimum KS distance, minimum CS and maximum LK value for a mix with $10 \%, 15 \%$ and $20 \%$ SF replacement. Accordingly, Lognormal and Weibull distribution were found to be the best fit models for mix with 10\%, 15\% and 20\% SF respectively. 
However, for mix with $0 \%, 5 \%, 25 \%$ and $30 \%$ SF, no single distribution meets all the test criteria but the values of all distributions are close to each other. Therefore, depending on KS distance and LK value, either Lognormal or the Weibull seems to be the closest fit model for these concrete mixes. For flexural strength, mix with 5\%, 15\% and 20\% SF, Weibull distribution meets all the selecting criteria. Similarly, for mix with $30 \%$ SF, lognormal distribution meets all the test criteria. However, no single distribution meets all the selecting criteria for mix with $0 \%, 10 \%$ and $25 \%$ SF. Based on KS and LK values, either of Weibull or lognormal distribution can be considered as the close fit distribution for these mixes. Similarly, for tensile strength, mix with $0 \%, 15 \%$ and $30 \%$ SF, a single distribution meets all the selecting criteria. Hence, lognormal, Gamma and Gamma distributions were found to be the best fit models for mix with $0 \%, 15 \%$ and 30\% SF respectively. No single distribution meets all the selecting criteria for mix with 5\%, 10\%, $20 \%$ and $25 \%$ SF. The probability distributions generated from the experimental results and the cumulative probability distribution models for compressive strength, flexural strength and tensile strength of SF concrete for different mix proportions of SF are shown in Figs. 6-8. The appropriate statistical distribution functions (with their respective shape and scale parameters) obtained for different mechanical properties of silica fume concrete are summarized in Table 8. It can be seen from this table that Weibull and Lognormal distribution function describe the variation of different mechanical properties of silica fume concrete most agreeably.

\section{PROBABILITY DISTRIBUTION MODEL AND SEISMIC FRAGILITY CURVES}

Having established the probabilistic representations of the variability in the mechanical properties of the SF concrete, it is prudent to study the effect of the proposed probability distributions of compressive strength in the performance of buildings through seismic fragility curves and reliability curves for the prediction of seismic performance of buildings constructed using SF concrete. A simplified method by Ellingwood (2001) was adopted in the present study for the development of fragility curves.

The seismic hazard curve, $G_{A}(x)$, a plot of $P[A=a]$ and the magnitude of ground acceleration $(a)$. The limit state probabilities of achieving a series of progressively severe stages, $L S_{i}$, are expressed as follows; 
The uncertainty in the above equation is referred as the seismic fragility, $F_{R}(x)$ and observed to follow a

2112014 and Haran et. al. 2015). A point estimate of the $L S_{i}$ of state $i$ can be calculated by combining the $212 F_{R}(x)$ with the derivative of $G_{A}(x)$, thus removing the acceleration condition,

$$
P\left[L S_{i}\right]=\int F_{R}(x) \frac{d G_{A}}{d x} d x
$$

214 The reliability index conforming to the failure probability can be predicted by the following standard 215 equation;

$$
\beta_{P f}=-\phi^{-1}\left(P\left[L S_{i}\right]\right)
$$

Where $\phi($ ) represents the standard normal distribution.

At moderate to large ground accelerations, a linear logarithmic relation exists between the annual probability of occurrence and the spectral acceleration. The hazard equation, $G A(a)$, suggested by Ellingwood (2001) can be described as follows;

$$
G_{A}(x)=1-\exp \left[-(x / u)^{-k}\right]
$$

where, $u$ and $k$ are the distribution parameters.

Nath and Thingbaijam (2012), Pallav et al. (2012), Raju et al. (2012) and Sitharam et al. (2015) have developed the seismic hazard curves for India and few studies (Iyengar et al. 2010 and Dhir et al. 2018) have considered the seismic hazard curves available at the National Disaster Management Authority for the seismic hazard analysis. In this study, seismic hazard curve of Imphal was selected (Fig. 7) being the most vulnerable location in seismic Zone V of India.

\section{FRAME CONSIDERED}


A typical RC bare frame having four stories (uniform story height of $3.2 \mathrm{~m}$ ) and two bays (uniform bay width of $5 \mathrm{~m}$ ) was considered. This building was designed for seismic force corresponding to highest seismic Zone V (Peak Ground Acceleration of 0.36g) as per IS 1893 (2002) and considering medium soil conditions ( $\mathrm{N}$-value in the range 10-30). The characteristic strength of concrete and steel were considered as $25 \mathrm{MPa}$ and $415 \mathrm{MPa}$, respectively. As the building is symmetric in plan and elevation, a single plane frame was shows the design details of the selected frame.

\section{Structural Modelling}

The Open System for Earthquake Engineering Simulation (OpenSEES) Laboratory tool developed by McKenna et al. (2014) was considered for all the analysis. A force-based nonlinear beam-column fiber element that considers the spread of plasticity along the element was used for modelling the beams and columns for nonlinear time history analysis. Formulation of the force-based fiber element was explained in Lee and Mosalam (2004). Kunnath (2007) has studied the sensitivity due to the number of integration points in each element and suggested the use of five integration points for nonlinear analysis of fiber elements, which was followed in the present study. The modelling of the core concrete performed by bearing in mind the influence of the special reinforcement detailing in the beams and columns suggested by Kent and Park 
(1971) and the cover concrete was modelled as unconfined concrete. Giuffre- Menegotto-Pinto steel material model was used for the modelling of steel reinforcing bars. Details of reinforcement modelling are available in Filippou et al. (1983).

In the current study, a lumped mass approach was taken in which all the permanent weights that move with the structure is lumped at the suitable nodes. It comprises of all the dead loads and part of the live load (25\%) that are expected to be present in the structure during the ground shaking. The in-plane stiffness of the floor was modelled using rigid diaphragm constraint. Damping was modelled using Raleigh damping for dynamic analysis, reported by Filippou et al. (1992). In this study, 44 ground motions (22 pairs) were considered (Haselton et al. 2012) and the details of the same are available in Haran et al. (2015). These ground motions were converted to match with IS 1893 (BIS 2002) design spectrum using a computer program (Mukherjee and Gupta 2002) and used for the nonlinear dynamic analyses. Uncertainties associated with concrete compressive strength, the yield strength of reinforcing steel, and global damping ratio were considered in the probabilistic seismic risk assessment. The mean value and coefficient of variation $(\mathrm{COV})$ of the normal probability distributions of the above parameters (uncorrelated) were obtained from published literature and presented in Table 10. Details of random variables used and assumptions of the computational modelling are available in Dhir et al. (2018).

\section{Development of Fragility Curves}

The fragility function represents the probability of exceedance of a selected Inter Storey Drift (ISD) for a selected structural limit state $(L S)$ for a specific ground motion Peak Ground Acceleration $(P G A)$ and the seismic fragility, $F_{R}(x)$ can be expressed as follows,

$$
P(D \geq C \mid \mathrm{PGA})=\varphi\left(\frac{\ln \frac{S_{D}}{S_{C}}}{\sqrt{\beta_{D \mid \mathrm{PGA}}^{2}+\beta_{c}^{2}}}\right)
$$

where, $C$ is the drift capacity at chosen limit state and $D$ is the drift demand, $S_{C}$ and $S_{D}$ are the median of the chosen limit state $(L S)$ and the demand respectively. $\beta_{c}$ and $\beta_{d / P G A}$ are dispersions in the capacities and 
$P G A$ respectively. $\beta_{c}$ is dependent on the construction quality and the building type considered. Depending on the quality of construction, the values of $\beta_{c}$ can be $0.10,0.25$ and 0.40 as good, fair and poor respectively

282 (ATC 58 2012) and in the present study it is assumed as 0.25. Many researchers (Nielson et. al. 2005; Davis et. al. 2010b; Rajeev and Tesfamariam 2012; Haran 2014, Haran et. al. 2015, Bhosale 2016, 2017, 2018; Dhir et al. 2018) have implemented this methodology to develop fragility curves of RC structures and its correctness has also been validated.

\section{Probabilistic Seismic Demand Model (PSDM)}

PSDMs for nonlinear time history analysis are given in terms of a suitable PGA. Cornell et.al (2002) suggested that the estimation of the median demand, $\operatorname{ISD}\left(S_{D}\right)$ can be calculated in a generalized equation (a power model) as per in Eq. 6.

$$
I S D=a(P G A)^{b}
$$

292 Where, $a$ and $b$ are the regression coefficients obtained from PSDMs.

\section{Performance limit states}

Limit states define the capacity of the structure to withstand different levels of damage. The median inter-storey drift limit states for both RC moment resisting infilled and bare frame structures defining the capacity of the structure at various performance levels $\left(S_{C}\right)$ are suggested by ASCE/SEI 41-06 (2007). Drift limits for RC frames as per ASCE/SEI 41-06 (2007) are considered in the present study as 2\% and 4\% for significant damage (SD) and near collapse (CP) performance levels respectively.

\section{Material uncertainty}

302 The most sensitive random variables such as compressive strength of concrete, yield strength of steel and 303 global damping ratio in a constructed building frame were considered as random. The mean and standard 304 deviations (in terms of COV) of all the random variables are presented in Table 11. Using Latin Hypercube 
sampling technique, a set of 44 values was produced to generate 44 computational models for conducting the nonlinear dynamic analysis.

\section{PSDMs for all frames}

The 44 earthquake ground motions were linearly scaled from $0.1 \mathrm{~g}$ to $1 \mathrm{~g}$ and each 44 computational models were analysed for a particular randomly selected earthquake with a particular PGA. The inter-storey drifts (maximum of all storeys) with the corresponding PGAs were plotted on a logarithmic graph for buildings with SF concrete as shown in Fig. 9. Using regression analysis, a power law (refer to Eq. 6) relationship for each frame, was fitted which represents the PSDM model for the corresponding frames. Higher the value of inter-storey drifts, the higher will be the vulnerability of the building. The regression coefficients ' $a$ ' and ' $b$ ', of the PSDMs, are found for each frame and reported in Table 12.

\section{Fragility Curves}

In order to study the performance of selected cases of building frames, the fragility curves are developed for all the frames for each performance limit states as shown in Fig. 10 for SF frames. Figs. 10a and 10b show the fragility curves at SD and CP performance levels respectively for SF frames. It can be seen from Figs. 10a and 10b that the SF frames with 15\%, 20\% and 25\% partial replacement of SF was found to be performing better than other frames for all performance limit states.

\section{Comparison of reliability indices}

In order to understand the performance of each frame quantitatively, the seismic reliability indices were calculated for each frame. The reliability indices were estimated by combining the fragility curve for a particular limit state and site seismic hazard curve (Eq. 2). In the present study, the hazard curve of North East India was chosen for reliability index estimation. Reliability index was calculated for two performance objectives, PO-II and PO-III, namely, Significant Damage (SD) performance level at an earthquake having a $10 \%$ probability of occurrence in 50 years (PO-II) and Collapse Prevention (CP) performance level at an 
earthquake having a $2 \%$ probability of occurrence in 50 years (PO-III). PGAs at $10 \%$ and $2 \%$ probability of occurrence were obtained from the hazard curve (Fig. 7) as $0.67 \mathrm{~g}$ and $1.35 \mathrm{~g}$ respectively. Reliability indices for different performance levels in terms of various PGA values are presented in Fig. 11 for SF buildings. Figs. 11a and 11b show the variation of reliability indices for different PGAs for all SF frames at SD and CP performance levels respectively. The PGAs corresponding to PO-II and PO-III performance

The reliability indices of all frames at PO-II and PO-III performance objectives are tabulated in Table 13. The seismic reliability of the SF concrete frames depends on many parameters including the statistics of the compressive strength of the SF concrete. Although it cannot be generalised, in order to understand the trend of the variation of seismic reliability at the two performance levels with the variation of replacement ratio of SF, a plot of normalised reliability (ratio of the seismic reliability index of the SF frames to the seismic reliability index of control frame) as shown in the Fig. 12 was considered. The equations representing the trend of the variation of the normalised reliability index with the variation of the SF ratio for the two performance objectives (PO-II and PO-III) and the corresponding coefficient of determination $\left(\mathrm{R}^{2}\right)$. The trend shows that the normalised seismic reliability index increases (for both PO-II and PO-III) initially, reaches an optimum at about 15 to $25 \%$ and then decreases with SF replacement ratio. Therefore, addition of SF in the range of $15 \%$ to $25 \%$ may yield better seismic performance.

\section{SUMMARY AND CONCLUSIONS}

The study of the statistical variations was carried out using the experimental data and considering several two parameter probability distribution functions with an aim to describe the variability of the mechanical properties of SF concrete. Several two-parameter distributions were selected to find the best-fit model that describes the experimental data closely. Based on the limited set of data and using three goodness-of-fit tests (minimum KS distance, minimum CS and maximum LK values), most appropriate statistical distributions for the selected parameters were proposed. The three selected statistical criteria (KS, CS and LK) are not always found to be in agreement with a single distribution for some of the concrete mixes. In 
such cases, the closest fit model was selected based on the KS distance and LK value (Chen et al. 2013). For other mixes, a single distribution was found to meet all the three validating criteria. This study proposed lognormal distribution function as the probability distribution model that most closely describes the variations of different mechanical properties of SF concrete from a practical viewpoint. Further, the performance of typically selected buildings using SF concrete was evaluated through fragility curves and reliability indices incorporating the proposed probability distributions and variability of material properties. It was found that $15 \%$ to $25 \%$ of partial replacement of cement with SF may yield better performance of the frames.

\section{REFERENCES}

ACI 234R-96 (Reapproved 2000), Guide for the Use of Silica Fume in Concrete, Reported by ACICommittee 234.

Applied Technology Council (ATC-58). (2007). Guidelines for Seismic Performance Assessment of Buildings.

ASCE/SEI Seismic Rehabilitation Standards Committee. (2007). Seismic rehabilitation of existing buildings (ASCE/SEI 41-06). American Society of Civil Engineers, Reston, VA.

ASTM, A. (2011). Standard specification for silica fume used in cementitious mixtures.

ASTM. (2012). Standard specification for slag cement for use in concrete and mortars.

Atiş, C. D., Özcan, F., Kılıc, A., Karahan, O., Bilim, C., \& Severcan, M. H. (2005). Influence of dry and wet curing conditions on compressive strength of silica fume concrete. Building and environment, 40(12), 1678-1683.

Bhosale, A. S., Davis, R., \& Sarkar, P. (2017). Vertical irregularity of buildings: Regularity index versus seismic risk. ASCE-ASME Journal of Risk and Uncertainty in Engineering Systems, Part A: Civil Engineering, 3(3), 04017001. 
Bhosale, A. S., Davis, R., \& Sarkar, P. (2018). Seismic Safety of Vertically Irregular Buildings: Performance of Existing Indicators. Journal of Architectural Engineering, 24(3), 04018013.

Bhosale, A., Davis, R., \& Sarkar, P. (2016). Sensitivity and Reliability Analysis of Masonry Infilled Frames. World Academy of Science, Engineering and Technology, International Journal of Civil, Environmental, Structural, Construction and Architectural Engineering, 10(12), 1531-1535.

BIS, I. (2002). Criteria for Earthquake Resistant Design of Structures Part 1 General Provisions and Buildings. Bureau of Indian Standards, Fifth revision. concrete. In Journal Proceedings (Vol. 64, No. 4, pp. 190-195). concrete frames subjected to Mid-America ground motions. Journal of Structural Engineering, 135(4).

394 Celik, O. C., \& Ellingwood, B. R. (2010). Seismic fragilities for non-ductile reinforced concrete frames395 Role of aleatoric and epistemic uncertainties. Structural Safety, 32(1), 1-12. Performance of Constructed Facilities, 28(4), 06014001.

398 Chmielewski, T., \& Konopka, E. (1999). Statistical evaluations of field concrete strength. Magazine of 399 concrete research, 51(1), 45-52.

400 Cornell, C. A., Jalayer, F., Hamburger, R. O., \& Foutch, D. A. (2001). The probabilistic basis for the 2000 401 SAC/FEMA steel moment frame guidelines. Submitted to. J. Struct. Engrg. 
Davis, P. R., Padhy, K. T., Menon, D., \& Prasad, A. M. (2010, July). Seismic fragility of open ground storey buildings in India. In 9th US National and 10th Canadian Conference on Earthquake Engineering.

Dhir, P. K., Davis, R., \& Sarkar, P. (2018). Safety Assessment of Gravity Load-Designed Reinforced Concrete-Framed Buildings. ASCE-ASME Journal of Risk and Uncertainty in Engineering Systems, Part A: Civil Engineering, 4(2), 04018004.

Ellingwood, B. R. (2001). Earthquake risk assessment of building structures. Reliability Engineering \& System Safety, 74(3), 251-262.

Filippou, F. C., D'ambrisi, A., \& Issa, A. (1992). Nonlinear static and dynamic analysis of reinforced concrete subassemblages. Earthquake Engineering Research Center, College of Engineering, University of California.

Ghobarah, A. (2001). Performance-based design in earthquake engineering: state of development. Engineering structures, 23(8), 878-884.

Graybeal, B., \& Davis, M. (2008). Cylinder or cube: strength testing of 80 to $200 \mathrm{MPa}$ (11.6 to $29 \mathrm{ksi})$ ultra-high-performance fiber-reinforced concrete. Materials Journal, 105(6), 603-609.

Haran, P. D. C. (2014). "Reliability based seismic design of open ground storey framed buildings." Ph.D. thesis, National Institute of Technology Rourkela, Rourkela, Orissa, India.

Haran, P. D. C., Bhosale, A., Davis, R. P., and Sarkar, P. (2016). "Multiplication factor for open ground storey buildings: A reliability based evaluation.” Earthquake Eng. Eng. Vibr., 15(2), 283-295.

Haran, P. D. C., Davis, R. P., and Sarkar, P. (2015). "Reliability evaluation of RC frame by two major fragility analysis methods.” Asian J. Civ. Eng., 16(1), 47-66.

Haselton, C. B., Whittaker, A. S., Hortacsu, A., Baker, J. W., Bray, J., \& Grant, D. N. (2012, September). Selecting and scaling earthquake ground motions for performing response-history analyses. In Proceedings of the 15th World Conference on Earthquake Engineering. 
IS: 383. (1970). Specification for coarse and fine aggregates from natural sources for concrete.

426

427

428

429

430

431

432

433

434

Iyengar, R. N., Chadha, R. K., Rao, K. B., and Raghukanth, S. T. G. (2010). "Development of probabilistic seismic hazard map of India.” Final Rep., National Disaster Management Authority, New Delhi, India.

Kent, D. C., and Park, R. (1971). “Flexural members with confined concrete.” J. Struct. Div., 97(7), 19691990.

Kunnath, S. K. (2006). Application of the PEER PBEE Methodology to the I-880 Viaduct: I-880 Testbed Committee. Pacific Earthquake Engineering Research (PEER) Center, College of Engineering, University of California.

Lee, T. H., \& Mosalam, K. M. (2004). Probabilistic fiber element modeling of reinforced concrete structures. Computers \& structures, 82(27), 2285-2299.

McKenna, F., McGann, C., Arduino, P., \& Harmon, J. A. (2013). OpenSEES laboratory.

Mukherjee, S., \& Gupta, V. K. (2002). Wavelet-based generation of spectrum-compatible timehistories. Soil Dynamics and Earthquake Engineering, 22(9-12), 799-804.

Nath SK, Thingbaijam KKS. Probabilistic Seismic hazard assessment of India, Seismological Research Letters, 2012:135-149.

Nielson, B. G. (2005). Analytical fragility curves for highway bridges in moderate seismic zones (Doctoral dissertation, Georgia Institute of Technology).

Pallav, K., Raghukanth, S.T.G. and Singh, K.D., (2012). Probabilistic seismic hazard estimation of Manipur, India. journal of geophysics and engineering, 9(5), p.516.

Poon, C. S., Kou, S. C., \& Lam, L. (2006). Compressive strength, chloride diffusivity and pore structure of high performance metakaolin and silica fume concrete. Construction and building materials, 20(10), 858865. 
447 Radonjanin, V., Malešev, M., Marinković, S., \& Al Malty, A. E. S. (2013). Green recycled aggregate 448 concrete. Construction and Building materials, 47, 1503-1511.

449 Rajeev, P., \& Tesfamariam, S. (2012). Seismic fragilities for reinforced concrete buildings with 450 consideration of irregularities. Structural Safety, 39, 1-13.

451 Raju KR, A Cinitha A, Iyer NR. Seismic performance evaluation of existing RC buildings designed as per 452 past codes of practice, Indian Academy of Sciences, 2002: Vol. 37, No. 2, April 2012, pp. 281-297.

453 Ranganathan, R. (1999). Structural reliability analysis and design. Jaico Publishing House.

454 Siddique, R. (2011). Utilization of silica fume in concrete: Review of hardened properties. Resources, 455 Conservation and Recycling, 55(11), 923-932.

456 Sitharam, T. G., Kolathayar, S., \& James, N. (2015). Probabilistic assessment of surface level seismic 457 hazard in India using topographic gradient as a proxy for site condition. Geoscience Frontiers, 6(6), 847$458 \quad 859$.

459 Song, J., \& Ellingwood, B. R. (1999). Seismic reliability of special moment steel frames with welded 460 connections: II. Journal of Structural Engineering, 125(4), 372-384.

461 Soroka, I. (1968). An application of statistical procedures to quality control of concrete. Materials and 462 Construction, 1 (5), 437-441.

463 Standard, I. (2004). Recommended guidelines for concrete mix design. Indian Standard 10262-1982.

464 Stone, W. C., Carino, N. J., \& Reeve, C. P. (1986, September). Statistical methods for in-place strength 465 predictions by the pullout test. In Journal Proceedings (Vol. 83, No. 5, pp. 745-756). 
Table 1. Mix proportions considered in the present study

\begin{tabular}{cccccccc}
\hline Mixture & Control & $5 \%$ SF & $10 \%$ SF & $15 \%$ SF & $20 \%$ SF & $25 \%$ SF & $30 \%$ SF \\
\hline Cement $\left(\mathrm{kg} / \mathrm{m}^{3}\right)$ & 308 & 322 & 305 & 288 & 272 & 254 & 237 \\
\hline Silica fume $\left(\mathrm{kg} / \mathrm{m}^{3}\right)$ & - & 16.8 & 33.8 & 50.8 & 67.8 & 84.8 & 101.8 \\
\hline Natural sand $\left(\mathrm{kg} / \mathrm{m}^{3}\right)$ & 715 & 702 & 700 & 698 & 695 & 694 & 692 \\
\hline Coarse aggregate $\left(\mathrm{kg} / \mathrm{m}^{3}\right)$ & 1304 & 1281 & 1278 & 1274 & 1269 & 1266 & 1262 \\
\hline$w / c$ & 0.48 & 0.43 & 0.43 & 0.43 & 0.43 & 0.43 & 0.43 \\
\hline Water $\left(\mathrm{kg} / \mathrm{m}^{3}\right)$ & 148 & 148 & 148 & 148 & 148 & 148 & 148 \\
\hline Admixture $\left(\mathrm{kg} / \mathrm{m}^{3}\right)$ & 1.23 & 2.71 & 3.05 & 3.39 & 3.73 & 4.07 & 4.41 \\
\hline
\end{tabular}

${ }^{*}$ Conversion factor $\mathrm{kg} / \mathrm{m}^{3}=$ multiply by $0.062428 \mathrm{lb} / \mathrm{ft}^{3}$ 
Table 2. Chemical and physical properties of Portland Slag Cement

\begin{tabular}{ccc}
\hline Chemical Requirements & Test Results & $\begin{array}{c}\text { Requirement as per IS:455- } \\
1989\end{array}$ \\
\hline Insoluble Residue (\% by mass) & 2.0 & 4.0 (Max) \\
\hline MgO \% by mass & 6.7 & 10.0 (Max) \\
\hline SO3 \%by mass & 1.8 & 3.0 (Max) \\
\hline S \% by mass & 0.2 & 1.5 (Max) \\
\hline $\begin{array}{c}\text { Specific Surface (blane) } \\
\mathrm{m}^{2} / \mathrm{kg}\end{array}$ & Physical Requirements & \\
\hline $\begin{array}{c}\text { Specific Gravity } \\
\end{array}$ & 343 & \\
\hline
\end{tabular}


Table 3. Chemical and physical properties of Silica Fume

\begin{tabular}{ccc}
\hline Parameter & Specification & Analysis \\
\hline $\mathrm{SiO}_{2} \%$ & 85.0 (Min) & 88.42 \\
\hline Moisture Content \% & 3.0 (Max) & 0.15 \\
\hline Loss of Ignition $\%$ & 6.0 (Max) & 1.50 \\
\hline Physical Requirements & 0.72 \\
\hline$>45$ Micron $\%$ & 10 (Max) & 137 \\
\hline Pozzolanic Activity $\mathrm{Index}(7 \mathrm{~d}) \%$ & 105 (Min) & 19.5 \\
\hline Specific Surface $\left(\mathrm{m}^{2} / \mathrm{g}\right)$ & 15 (Min) & 615 \\
\hline Bulk Density $\left(\mathrm{kg} / \mathrm{m}^{3}\right)$ & $500-700$ & \\
\hline
\end{tabular}


Table 4. Compressive Strength, Flexural Strength and Tensile Splitting Strength of SF Concrete

\begin{tabular}{|c|c|c|c|c|c|c|c|c|c|}
\hline \multirow[t]{2}{*}{ Specimen } & \multicolumn{3}{|c|}{$\begin{array}{c}\text { Compressive Strength } \\
(\mathrm{MPa})\end{array}$} & \multicolumn{3}{|c|}{ Flexural Strength (MPa) } & \multicolumn{3}{|c|}{$\begin{array}{l}\text { Tensile Splitting Strength } \\
\text { (MPa) }\end{array}$} \\
\hline & Mean & SD & Range & Mean & SD & Range & Mean & SD & Range \\
\hline Control & 30.37 & 2.71 & $\begin{array}{l}24.18- \\
34.60\end{array}$ & 6.32 & 0.33 & $\begin{array}{r}5.94- \\
6.82\end{array}$ & 2.60 & 0.23 & $\begin{array}{c}2.18- \\
2.96\end{array}$ \\
\hline $5 \% \mathrm{SF}$ & 30.73 & 4.17 & $\begin{array}{l}18.73- \\
38.01\end{array}$ & 6.39 & 0.74 & $\begin{array}{r}4.10- \\
7.44 \\
\end{array}$ & 3.02 & 0.31 & $\begin{array}{c}2.51- \\
3.60 \\
\end{array}$ \\
\hline $10 \% \mathrm{SF}$ & 43.97 & 3.79 & $\begin{array}{l}37.46- \\
50.98\end{array}$ & 6.60 & 0.50 & $\begin{array}{l}5.66- \\
7.41\end{array}$ & 3.02 & 0.30 & $\begin{array}{c}2.50- \\
3.62\end{array}$ \\
\hline $15 \% \mathrm{SF}$ & 47.42 & 6.29 & $\begin{array}{l}37.75- \\
60.82\end{array}$ & 6.62 & 0.29 & $\begin{array}{l}6.05- \\
7.02\end{array}$ & 3.59 & 0.46 & $\begin{array}{c}2.85- \\
4.33\end{array}$ \\
\hline $20 \%$ SF & 53.97 & 6.18 & $\begin{array}{l}43.71- \\
62.86\end{array}$ & 7.10 & 0.31 & $\begin{array}{c}6.56- \\
7.51\end{array}$ & 3.91 & 0.31 & $\begin{array}{l}3.44 \\
4.33\end{array}$ \\
\hline $25 \% \mathrm{SF}$ & 49.06 & 5.96 & $\begin{array}{l}41.26- \\
62.52\end{array}$ & 8.35 & 0.48 & $\begin{array}{l}7.36- \\
9.10\end{array}$ & 3.78 & 0.38 & $\begin{array}{l}3.14- \\
4.32\end{array}$ \\
\hline $30 \%$ SF & 45.11 & 8.03 & $\begin{array}{r}29.94- \\
62.30\end{array}$ & 7.46 & 0.26 & $\begin{array}{l}7.13- \\
7.94\end{array}$ & 3.80 & 0.45 & $\begin{array}{c}3.17- \\
4.51\end{array}$ \\
\hline
\end{tabular}

*Conversion factor $\mathrm{MPa}=$ multiply by $0.1450 \mathrm{ksi}$ 
Table 5. Estimated Parameters, KS Distances, LK, and CS for Different Distribution Functions describing Compressive Strength

\begin{tabular}{|c|c|c|c|c|c|c|}
\hline Mix Name & Distribution & Shape & Scale & $\mathrm{KS}$ & CS & LK \\
\hline \multirow{4}{*}{ Control } & Weibull & 13.49 & 31.57 & 0.077 & 0.648 & -71.49 \\
\hline & Gamma & 125.85 & 0.2414 & 0.073 & 0.88 & -72.37 \\
\hline & Normal & 30.376 & 2.717 & 0.062 & 0.713 & -72.05 \\
\hline & Lognormal & 0.091 & 30.23 & 0.072 & 0.76 & -72.58 \\
\hline \multirow{4}{*}{$5 \% \mathrm{SF}$} & Weibull & 8.96 & 32.47 & 0.076 & 1.83 & -84.04 \\
\hline & Gamma & 51.31 & 0.59 & 0.077 & 1.70 & -86.06 \\
\hline & Normal & 30.738 & 4.179 & 0.067 & 1.77 & -84.97 \\
\hline & Lognormal & 0.146 & 30.416 & 0.082 & 1.36 & -86.81 \\
\hline \multirow{4}{*}{$10 \% \mathrm{SF}$} & Weibull & 12.56 & 45.73 & 0.164 & 2.29 & -83.58 \\
\hline & Gamma & 140.35 & 0.313 & 0.147 & 0.90 & -81.84 \\
\hline & Normal & 43.97 & 3.797 & 0.151 & 0.97 & -82.09 \\
\hline & Lognormal & 0.085 & 43.816 & 0.141 & 0.70 & -81.75 \\
\hline \multirow{4}{*}{$15 \% \mathrm{SF}$} & Weibull & 8.136 & 50.211 & 0.188 & 3.22 & -98.61 \\
\hline & Gamma & 59.706 & 0.794 & 0.167 & 0.99 & -96.83 \\
\hline & Normal & 47.425 & 6.298 & 0.175 & 1.49 & -97.27 \\
\hline & Lognormal & 0.131 & 46.993 & 0.157 & 0.79 & -96.70 \\
\hline \multirow{4}{*}{$20 \% \mathrm{SF}$} & Weibull & 11.181 & 66.387 & 0.179 & 2.27 & -95.01 \\
\hline & Gamma & 77.657 & 0.692 & 0.204 & 4.06 & -96.69 \\
\hline & Normal & 53.773 & 6.091 & 0.183 & 3.07 & -96.27 \\
\hline & Lognormal & 0.116 & 53.410 & 0.192 & 3.75 & -96.97 \\
\hline \multirow{4}{*}{$25 \% \mathrm{SF}$} & Weibull & 8.418 & 51.76 & 0.386 & 2.72 & -97.92 \\
\hline & Gamma & 72.55 & 0.676 & 0.412 & 0.41 & -94.96 \\
\hline & Normal & 49.067 & 5.963 & 0.406 & 0.79 & -95.63 \\
\hline & Lognormal & 0.118 & 48.715 & 0.409 & 0.33 & -94.70 \\
\hline \multirow{4}{*}{$30 \% \mathrm{SF}$} & Weibull & 6.29 & 48.425 & 0.448 & 0.84 & -104.99 \\
\hline & Gamma & 31.425 & 1.435 & 0.446 & 1.88 & -104.80 \\
\hline & Normal & 45.114 & 8.039 & 0.444 & 1.44 & -104.59 \\
\hline & Lognormal & 0.1843 & 44.389 & 0.433 & 1.92 & -105.13 \\
\hline
\end{tabular}


Table 6. Estimated Parameters, KS Distances, LK, and CS for Different Distribution Functions describing Flexural Strength

\begin{tabular}{|c|c|c|c|c|c|c|}
\hline Mix Name & Distribution & Shape & Scale & KS & CS & LK \\
\hline \multirow{4}{*}{ Control } & Weibull & 22.707 & 6.477 & 0.142 & - & -5.761 \\
\hline & Gamma & 374.401 & 0.016 & 0.105 & - & -6.001 \\
\hline & Normal & 6.326 & 0.333 & 0.106 & - & -5.919 \\
\hline & Lognormal & 0.0532 & 6.296 & 0.097 & - & -6.071 \\
\hline \multirow{4}{*}{$5 \% \mathrm{SF}$} & Weibull & 11.376 & 6.695 & 0.080 & - & -20.344 \\
\hline & Gamma & 67.395 & 0.094 & 0.121 & - & -23.293 \\
\hline & Normal & 6.398 & 0.074 & 0.086 & - & -22.093 \\
\hline & Lognormal & 0.129 & 6.347 & 0.114 & - & -24.023 \\
\hline \multirow{4}{*}{$10 \% \mathrm{SF}$} & Weibull & 16.135 & 6.827 & 0.152 & - & -13.641 \\
\hline & Gamma & 178.158 & 0.037 & 0.117 & - & -14.274 \\
\hline & Normal & 6.606 & 0.502 & 0.118 & - & -14.109 \\
\hline & Lognormal & 0.077 & 6.586 & 0.106 & - & -14.394 \\
\hline \multirow{4}{*}{$15 \% \mathrm{SF}$} & Weibull & 28.821 & 6.757 & 0.118 & - & -2.436 \\
\hline & Gamma & 529.181 & 0.012 & 0.137 & - & -3.463 \\
\hline & Normal & 6.621 & 0.293 & 0.155 & - & -3.343 \\
\hline & Lognormal & 0.044 & 6.612 & 0.159 & - & -3.540 \\
\hline \multirow{4}{*}{$20 \% \mathrm{SF}$} & Weibull & 30.797 & 7.239 & 0.107 & - & -2.949 \\
\hline & Gamma & 520.572 & 0.013 & 0.526 & - & -5.100 \\
\hline & Normal & 7.107 & 0.315 & 0.155 & - & -4.824 \\
\hline & Lognormal & 0.045 & 7.113 & 0.163 & - & -5.171 \\
\hline \multirow{4}{*}{$25 \% \mathrm{SF}$} & Weibull & 21.944 & 8.567 & 0.147 & - & -12.472 \\
\hline & Gamma & 300.758 & 0.027 & 0.529 & - & -13.749 \\
\hline & Normal & 8.353 & 0.488 & 0.143 & - & -13.530 \\
\hline & Lognormal & 0.059 & 8.39 & 0.143 & - & -13.886 \\
\hline \multirow{4}{*}{$30 \% \mathrm{SF}$} & Weibull & 30.725 & 7.587 & 0.123 & - & -2.405 \\
\hline & Gamma & 829.575 & 0.009 & 0.135 & - & -1.358 \\
\hline & Normal & 7.46 & 0.266 & 0.123 & - & -1.402 \\
\hline & Lognormal & 0.0356 & 7.455 & 0.125 & - & -1.351 \\
\hline
\end{tabular}


Table 7. Estimated Parameters, KS Distances, LK, and CS for Different Distribution Functions describing Tensile Splitting Strength

\begin{tabular}{|c|c|c|c|c|c|c|}
\hline Mix Name & Distribution & Shape & Scale & KS & $\mathrm{CS}$ & LK \\
\hline \multirow{4}{*}{ Control } & Weibull & 13.597 & 2.707 & 0.107 & - & -1.457 \\
\hline & Gamma & 123.064 & 0.212 & 0.110 & - & -0.653 \\
\hline & Normal & 2.604 & 0.237 & 0.102 & - & -0.873 \\
\hline & Lognormal & 0.0933 & 2.585 & 0.102 & - & -0.503 \\
\hline \multirow{4}{*}{$5 \% \mathrm{SF}$} & Weibull & 10.213 & 10.213 & 0.186 & - & -5.969 \\
\hline & Gamma & 99.679 & 0.03 & 0.106 & - & -4.525 \\
\hline & Normal & 3.302 & 0.313 & 0.159 & - & -4.675 \\
\hline & Lognormal & 0.1025 & 3.007 & 0.141 & - & -4.336 \\
\hline \multirow{4}{*}{$10 \% \mathrm{SF}$} & Weibull & 10.467 & 3.161 & 0.14 & - & -5.465 \\
\hline & Gamma & 103.881 & 0.029 & 0.07 & - & -4.006 \\
\hline & Normal & 3.022 & 0.306 & 0.09 & - & -4.217 \\
\hline & Lognormal & 0.1005 & 3.007 & 0.08 & - & -3.957 \\
\hline \multirow{4}{*}{$15 \% \mathrm{SF}$} & Weibull & 8.773 & 3.795 & 0.154 & - & -13.118 \\
\hline & Gamma & 61.461 & 0.058 & 0.122 & - & -12.656 \\
\hline & Normal & 3.591 & 0469 & 0.143 & - & -49.661 \\
\hline & Lognormal & 0.1312 & 3.560 & 0.131 & - & -12.668 \\
\hline \multirow{4}{*}{$20 \% \mathrm{SF}$} & Weibull & 15.074 & 4.055 & 1.588 & - & -4.683 \\
\hline & Gamma & 158.572 & 0.0247 & 1.626 & - & -4.968 \\
\hline & Normal & 3.913 & 0.317 & 1.56 & - & -4.929 \\
\hline & Lognormal & 0.081 & 3.900 & 1.557 & - & -5.020 \\
\hline \multirow{4}{*}{$25 \% \mathrm{SF}$} & Weibull & 12.305 & 3.949 & 0.12 & - & -8.182 \\
\hline & Gamma & 98.141 & 0.038 & 0.12 & - & -9.053 \\
\hline & Normal & 3.782 & 0.386 & 0.11 & - & -8.842 \\
\hline & Log Normal & 0.104 & 3.762 & 0.11 & - & -9.206 \\
\hline \multirow{4}{*}{$30 \% \mathrm{SF}$} & Weibull & 9.739 & 4.005 & 0.159 & - & -12.301 \\
\hline & Gamma & 74.27 & 0.057 & 0.106 & - & -11.951 \\
\hline & Normal & 3.806 & 0.452 & 0.135 & - & -12.023 \\
\hline & Lognormal & 0.119 & 3.781 & 0.119 & - & -11.971 \\
\hline
\end{tabular}


Table 8. Most Appropriate Statistical Distribution Functions for Mechanical Properties of SF Concrete

\begin{tabular}{cccc}
\hline Dosage of SF (\%) & Compressive Strength & Flexural Strength & Tensile Splitting \\
\hline 0 & Weibull & Lognormal & Lognormal \\
& $(13.490,31.570)$ & $(0.053,6.296)$ & $(0.093,2.585)$ \\
\hline 5 & Weibull & Weibull & Gamma \\
& $(8.960,32.470)$ & $(11.376,6.695)$ & $(99.679,0.030)$ \\
\hline 10 & Lognormal & Lognormal & Lognormal \\
& $(0.085,43.816)$ & $(0.077,6.586)$ & $(0.101,3.007)$ \\
\hline 15 & Lognormal & Weibull & Gamma \\
& $(0.131,46.993)$ & $(28.821,6.757)$ & $(61.461,0.058)$ \\
\hline 20 & Weibull & Weibull & Weibull \\
& $(11.181,66.387)$ & $(30.797,7.239)$ & $(15.074,4.055)$ \\
\hline 25 & Lognormal & Weibull & Weibull \\
& $(0.118,48.715)$ & $(21.944,8.567)$ & $(12.305,3.949)$ \\
\hline \multirow{2}{*}{30} & Weibull & Lognormal & Gamma \\
& $(6.290,48.425)$ & $(0.036,7.455)$ & $(74.270,0.057)$ \\
\hline
\end{tabular}

Note: The figures in the bracket denote the shape and scale parameters of each distribution respectively 
Table 9. Design details of the selected building frame

\begin{tabular}{cccccc}
\hline Member & $\begin{array}{c}\text { Floor no./ } \\
\text { Storey no. }\end{array}$ & $\begin{array}{l}\text { Width } \\
(\mathrm{mm})\end{array}$ & $\begin{array}{c}\text { Depth } \\
(\mathrm{mm})\end{array}$ & $\begin{array}{c}\text { Longitudinal } \\
\text { Reinforcement detail }\end{array}$ & $\begin{array}{c}\text { Transverse } \\
\text { Reinforcement detail }\end{array}$ \\
\hline Beam & 1 to 3 & 300 & 450 & $\begin{array}{c}{[5-25 \varphi](\text { Top) }+[4-20 \varphi]} \\
\text { (Bottom) }\end{array}$ & $10 \varphi @ 100 \mathrm{c} / \mathrm{c}$ \\
\hline Beam & 4 & 300 & 450 & $\begin{array}{c}{[5-25 \varphi] \text { (Top) }+[4-16 \varphi]} \\
\text { (Bottom) }\end{array}$ & $10 \varphi @ 100 \mathrm{c} / \mathrm{c}$ \\
\hline Column & $1-4$ & 350 & 350 & $\begin{array}{c}8-25 \text { (Uniformly } \\
\text { distributed) }\end{array}$ & $10 \varphi @ 175 \mathrm{c} / \mathrm{c}$ \\
\hline
\end{tabular}


Table 10. Details of random variables used

\begin{tabular}{ccccc}
\hline Random variables & Mean & COV (\%) & $\begin{array}{c}\text { Probability } \\
\text { Distribution }\end{array}$ & Source \\
\hline $\begin{array}{c}\text { Concrete compressive } \\
\text { strength }\end{array}$ & $33.66 \mathrm{MPa}$ & 21.0 & Normal & Ranganathan (1999) \\
\hline Steel yield strength & $483.47 \mathrm{MPa}$ & 10.0 & Normal & Ranganathan (1999) \\
\hline Global damping ratio & $5 \%$ & 76.0 & Lognormal & $\begin{array}{c}\text { Celik and } \\
\text { Ellingwood (2009) }\end{array}$ \\
\hline
\end{tabular}


Table 11. Compressive strength of concrete of various buildings

\begin{tabular}{ccccc}
\hline Frame ID & Mean (MPa / \%) & C.O.V (\%) & Distribution & Source \\
\hline C & 30.28 & 8.94 & Lognormal & Present study \\
\hline SF5 & 30.73 & 13.56 & Lognormal & Present study \\
\hline SF10 & 43.97 & 8.61 & Lognormal & Present study \\
\hline SF15 & 47.42 & 13.26 & Lognormal & Present study \\
\hline SF20 & 53.97 & 11.45 & Lognormal & Present study \\
\hline SF25 & 49.06 & 12.14 & Lognormal & Present study \\
\hline SF30 & 45.11 & 17.80 & Lognormal & Present study \\
\hline
\end{tabular}


Table 12. PSDM models for all the frames

\begin{tabular}{cccc}
\hline Frame ID & $a(P G A)^{b}$ & $a$ & $b$ \\
\hline C & $2.58(P G A)^{0.62}$ & 2.58 & 0.62 \\
\hline SF5 & $2.45(P G A)^{0.61}$ & 2.45 & 0.61 \\
\hline SF10 & $2.92(P G A)^{0.79}$ & 2.92 & 0.79 \\
\hline SF15 & $2.84(P G A)^{0.80}$ & 2.84 & 0.80 \\
\hline SF20 & $3.26(P G A)^{0.86}$ & 3.26 & 0.86 \\
\hline SF25 & $2.77(P G A)^{0.77}$ & 2.77 & 0.77 \\
\hline SF30 & $3.06(P G A)^{0.81}$ & 3.06 & 0.81 \\
\hline
\end{tabular}


Table 13. Reliability index $\left(\mathrm{P}_{\mathrm{f}}\right)$ for SF building frames

\begin{tabular}{lcc}
\hline Frame ID & PO-II, $\beta_{\mathrm{Pf}}\left(\mathrm{P}_{\mathrm{f}}\right)$ & PO-III, $\beta_{\mathrm{Pf}}\left(\mathrm{P}_{\mathrm{f}}\right)$ \\
\hline C & $1.07(1.423 \mathrm{E}-01)$ & $1.76(3.920 \mathrm{E}-02)$ \\
\hline SF5 & $1.14(1.271 \mathrm{E}-01)$ & $1.85(3.216 \mathrm{E}-02)$ \\
\hline SF10 & $1.39(8.226 \mathrm{E}-02)$ & $1.98(2.385 \mathrm{E}-02)$ \\
\hline SF15 & $1.42(7.780 \mathrm{E}-02)$ & $2.00(2.275 \mathrm{E}-02)$ \\
\hline SF20 & $1.41(7.927 \mathrm{E}-02)$ & $1.95(2.559 \mathrm{E}-02)$ \\
\hline SF25 & $1.42(7.780 \mathrm{E}-02)$ & $2.03(2.118 \mathrm{E}-02)$ \\
\hline SF30 & $1.14(1.271 \mathrm{E}-01)$ & $1.68(4.648 \mathrm{E}-02)$ \\
\hline
\end{tabular}




\section{APPENDIX}

Table 1A. Compressive Strength of SF Concrete (in MPa)

\begin{tabular}{|c|c|c|c|c|c|c|c|}
\hline Sl. No. & Control & $5 \% \mathrm{SF}$ & $10 \% \mathrm{SF}$ & $15 \% \mathrm{SF}$ & $20 \% \mathrm{SF}$ & $25 \% \mathrm{SF}$ & $30 \% \mathrm{SF}$ \\
\hline 1 & 24.18 & 18.73 & 37.46 & 37.75 & 43.71 & 41.26 & 29.94 \\
\hline 2 & 26.23 & 25.42 & 39.56 & 38.77 & 43.74 & 41.41 & 30.54 \\
\hline 3 & 26.66 & 25.78 & 39.68 & 39.39 & 44.37 & 41.52 & 34.07 \\
\hline 4 & 26.76 & 26.29 & 39.98 & 39.48 & 44.78 & 42.34 & 34.15 \\
\hline 5 & 27.26 & 26.55 & 40.21 & 41.08 & 45.23 & 42.57 & 34.22 \\
\hline 6 & 27.41 & 26.57 & 40.43 & 41.29 & 46.81 & 43.18 & 37.84 \\
\hline 7 & 27.81 & 26.68 & 40.50 & 42.70 & 46.84 & 44.21 & 39.38 \\
\hline 8 & 28.54 & 27.34 & 40.51 & 43.44 & 48.23 & 44.26 & 40.50 \\
\hline 9 & 28.64 & 29.11 & 40.72 & 43.52 & 48.28 & 44.47 & 40.71 \\
\hline 10 & 28.84 & 29.18 & 41.29 & 43.89 & 48.83 & 46.01 & 41.19 \\
\hline 11 & 29.21 & 29.23 & 41.71 & 44.24 & 51.78 & 46.03 & 41.19 \\
\hline 12 & 29.72 & 29.55 & 41.74 & 44.32 & 52.51 & 46.13 & 44.27 \\
\hline 13 & 29.83 & 29.64 & 41.86 & 44.38 & 54.47 & 46.18 & 44.50 \\
\hline 14 & 30.22 & 30.02 & 42.15 & 44.49 & 55.88 & 46.24 & 44.61 \\
\hline 15 & 30.51 & 30.46 & 42.81 & 44.56 & 56.77 & 46.77 & 45.81 \\
\hline 16 & 30.98 & 31.59 & 43.65 & 45.27 & 57.51 & 48.16 & 46.65 \\
\hline 17 & 31.17 & 32.14 & 43.88 & 45.82 & 57.59 & 49.68 & 46.71 \\
\hline 18 & 31.34 & 32.53 & 44.55 & 47.30 & 58.17 & 50.12 & 47.05 \\
\hline 19 & 31.52 & 32.91 & 45.16 & 50.15 & 58.25 & 50.34 & 48.10 \\
\hline 20 & 31.56 & 33.15 & 45.40 & 50.35 & 58.28 & 50.66 & 48.11 \\
\hline 21 & 31.82 & 33.30 & 46.80 & 51.76 & 58.34 & 51.59 & 48.26 \\
\hline 22 & 32.57 & 33.44 & 47.17 & 52.64 & 58.38 & 53.12 & 49.18 \\
\hline 23 & 32.81 & 33.45 & 47.36 & 53.61 & 58.41 & 53.16 & 49.78 \\
\hline 24 & 32.81 & 33.64 & 47.53 & 53.64 & 58.69 & 53.28 & 50.74 \\
\hline 25 & 32.85 & 34.55 & 47.93 & 54.40 & 58.86 & 54.35 & 50.75 \\
\hline 26 & 33.28 & 34.63 & 48.98 & 54.83 & 58.97 & 56.06 & 52.33 \\
\hline 27 & 33.57 & 35.25 & 49.17 & 55.27 & 59.89 & 56.13 & 53.65 \\
\hline 28 & 34.11 & 35.46 & 49.72 & 56.29 & 60.54 & 58.96 & 57.86 \\
\hline 29 & 34.29 & 37.43 & 50.14 & 57.18 & 62.12 & 61.17 & 58.92 \\
\hline 30 & 34.60 & 38.01 & 50.98 & 60.82 & 62.86 & 62.52 & 62.30 \\
\hline Mean & 30.37 & 30.73 & 43.97 & 47.42 & 53.97 & 49.06 & 45.11 \\
\hline SD & 2.71 & 4.17 & 3.79 & 6.29 & 6.18 & 5.96 & 8.03 \\
\hline
\end{tabular}

*Conversion factor $\mathrm{MPa}=$ multiply by $0.1450 \mathrm{ksi}$ 
Table 2A. Flexural Strength (MPa) of SF Concrete

\begin{tabular}{|c|c|c|c|c|c|c|c|}
\hline Sl No. & Control & $5 \% \mathrm{SF}$ & $10 \% \mathrm{SF}$ & $15 \% \mathrm{SF}$ & $20 \% \mathrm{SF}$ & $25 \% \mathrm{SF}$ & $30 \% \mathrm{SF}$ \\
\hline 1 & 5.94 & 7.01 & 6.86 & 6.32 & 7.12 & 7.87 & 7.15 \\
\hline 2 & 6.12 & 5.94 & 7.01 & 6.51 & 7.25 & 8.81 & 7.62 \\
\hline 3 & 6.47 & 5.98 & 6.54 & 6.48 & 7.23 & 8.75 & 7.13 \\
\hline 4 & 6.81 & 4.10 & 6.31 & 6.92 & 6.71 & 7.93 & 7.73 \\
\hline 5 & 6.06 & 5.73 & 5.88 & 6.56 & 6.58 & 8.43 & 7.94 \\
\hline 6 & 6.65 & 5.87 & 6.23 & 6.14 & 6.56 & 8.15 & 7.50 \\
\hline 7 & 6.16 & 7.42 & 6.27 & 6.78 & 7.16 & 8.21 & 7.66 \\
\hline 8 & 5.96 & 6.58 & 6.65 & 6.24 & 7.23 & 8.75 & 7.40 \\
\hline 9 & 6.82 & 6.41 & 5.75 & 6.05 & 7.49 & 8.50 & 7.31 \\
\hline 10 & 6.52 & 6.54 & 7.09 & 6.87 & 6.85 & 9.10 & 7.89 \\
\hline 11 & 5.63 & 6.53 & 7.24 & 6.82 & 7.41 & 7.36 & 7.23 \\
\hline 12 & 6.47 & 6.11 & 5.66 & 6.80 & 7.33 & 8.81 & 7.08 \\
\hline 13 & 6.15 & 7.14 & 7.41 & 6.59 & 7.25 & 8.75 & 7.15 \\
\hline 14 & 6.70 & 5.82 & 6.90 & 6.81 & 7.51 & 8.43 & 7.62 \\
\hline 15 & 5.87 & 6.17 & 6.72 & 6.99 & 7.30 & 8.15 & 7.66 \\
\hline 16 & 6.65 & 7.03 & 6.25 & 6.78 & 7.11 & 7.36 & 7.40 \\
\hline 17 & 6.19 & 6.75 & 6.94 & 6.27 & 6.46 & 8.81 & 7.31 \\
\hline 18 & 6.50 & 6.69 & 7.05 & 7.02 & 7.15 & 8.75 & 7.50 \\
\hline 19 & 6.34 & 7.44 & 6.28 & 6.88 & 7.41 & 7.93 & 7.73 \\
\hline 20 & 6.41 & 6.63 & 6.99 & 6.51 & 6.96 & 8.15 & 7.13 \\
\hline Mean & 6.32 & 6.39 & 6.60 & 6.62 & 7.10 & 8.35 & 7.46 \\
\hline SD & 0.33 & 0.74 & 0.50 & 0.29 & 0.31 & 0.48 & 0.26 \\
\hline
\end{tabular}

*Conversion factor $\mathrm{MPa}=$ multiply by $0.1450 \mathrm{ksi}$ 
Table 3A. Tensile Splitting Strength (MPa) of SF Concrete

\begin{tabular}{|c|c|c|c|c|c|c|c|}
\hline Sl. No. & Control & $5 \% \mathrm{SF}$ & $10 \% \mathrm{SF}$ & $15 \% \mathrm{SF}$ & $20 \% \mathrm{SF}$ & $25 \% \mathrm{SF}$ & $30 \% \mathrm{SF}$ \\
\hline 1 & 2.21 & 2.51 & 2.50 & 2.85 & 3.44 & 3.14 & 3.17 \\
\hline 2 & 2.69 & 2.57 & 2.60 & 2.95 & 3.48 & 3.17 & 3.20 \\
\hline 3 & 2.64 & 2.66 & 2.67 & 2.99 & 3.52 & 3.24 & 3.24 \\
\hline 4 & 2.71 & 2.75 & 2.73 & 3.17 & 3.54 & 3.28 & 3.27 \\
\hline 5 & 2.67 & 2.81 & 2.79 & 3.20 & 3.57 & 3.36 & 3.31 \\
\hline 6 & 2.57 & 2.85 & 2.83 & 3.22 & 3.61 & 3.53 & 3.48 \\
\hline 7 & 2.46 & 2.88 & 2.86 & 3.27 & 3.71 & 3.57 & 3.52 \\
\hline 8 & 2.54 & 2.91 & 2.90 & 3.28 & 3.74 & 3.69 & 3.55 \\
\hline 9 & 2.67 & 2.93 & 2.94 & 3.48 & 3.76 & 3.78 & 3.58 \\
\hline 10 & 2.26 & 2.95 & 2.97 & 3.51 & 3.79 & 3.81 & 3.83 \\
\hline 11 & 2.61 & 2.96 & 3.02 & 3.53 & 4.06 & 3.86 & 3.86 \\
\hline 12 & 2.29 & 2.97 & 3.05 & 3.59 & 4.10 & 3.92 & 3.89 \\
\hline 13 & 2.73 & 3.02 & 3.08 & 3.83 & 4.14 & 3.96 & 3.96 \\
\hline 14 & 2.85 & 3.08 & 3.10 & 3.90 & 4.17 & 4.03 & 4.11 \\
\hline 15 & 2.18 & 3.17 & 3.17 & 3.92 & 4.18 & 4.12 & 4.14 \\
\hline 16 & 2.81 & 3.27 & 3.20 & 4.10 & 4.21 & 4.15 & 4.26 \\
\hline 17 & 2.35 & 3.39 & 3.32 & 4.15 & 4.24 & 4.19 & 4.33 \\
\hline 18 & 2.88 & 3.51 & 3.48 & 4.22 & 4.27 & 4.20 & 4.39 \\
\hline 19 & 2.90 & 3.55 & 3.53 & 4.24 & 4.30 & 4.21 & 4.44 \\
\hline 20 & 2.96 & 3.60 & 3.62 & 4.33 & 4.33 & 4.32 & 4.51 \\
\hline Mean & 2.60 & 3.02 & 3.02 & 3.59 & 3.91 & 3.78 & 3.80 \\
\hline SD & 0.23 & 0.31 & 0.30 & 0.46 & 0.31 & 0.38 & 0.45 \\
\hline
\end{tabular}

*Conversion factor $\mathrm{MPa}=$ multiply by $0.1450 \mathrm{ksi}$ 


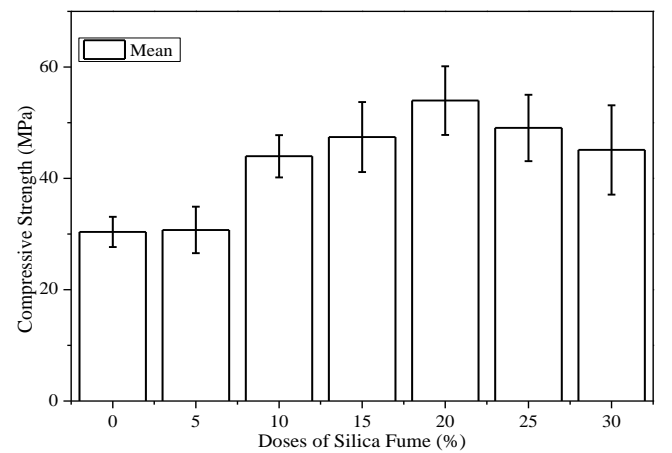

Fig. 1. Variation of Mean, SD of Compressive Strength (Conversion factor MPa= multiply by $0.1450 \mathrm{ksi}$ ) 
Fig. 2

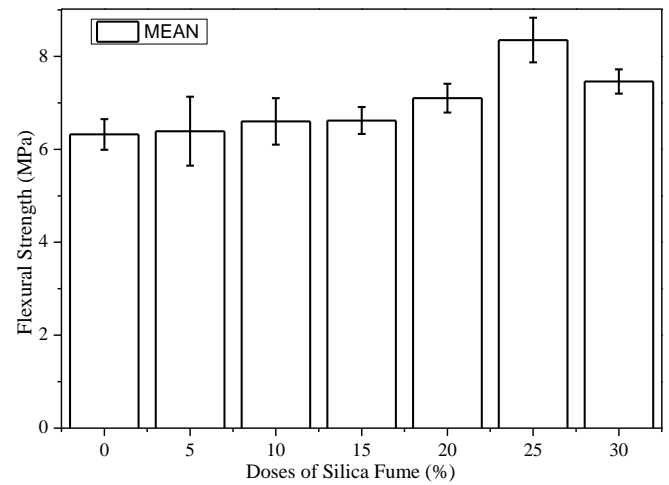

Fig. 2. Variation of Mean, SD of Flexural Strength (Conversion factor MPa= multiply by $0.1450 \mathrm{ksi}$ ) 
Fig. 3

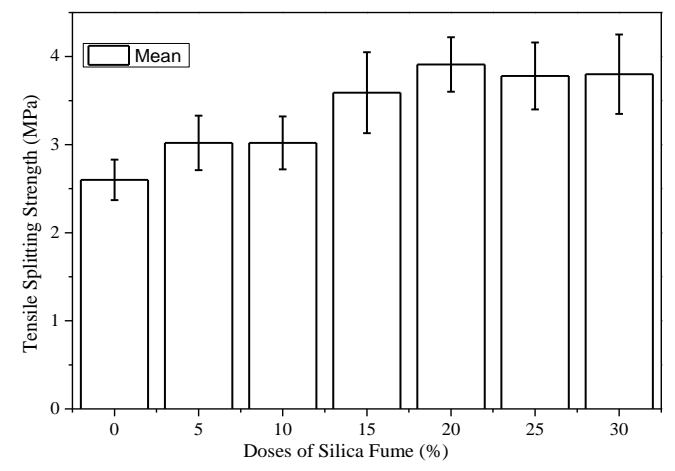

Fig.3. Variation of Mean, SD of Tensile Strength (Conversion factor MPa= multiply by $0.1450 \mathrm{ksi}$ ) 


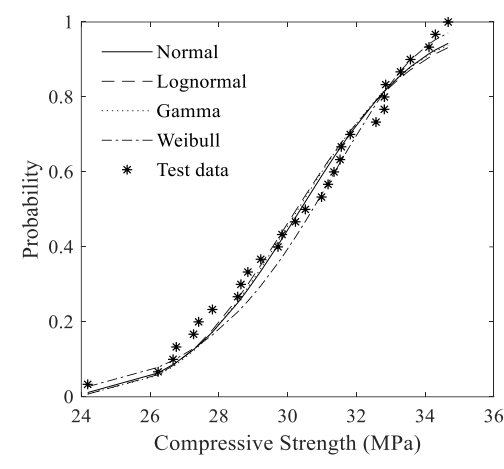

(a) Control

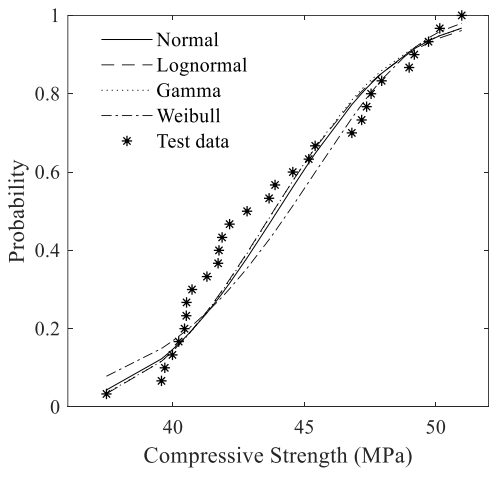

(c) $10 \% \mathrm{SF}$

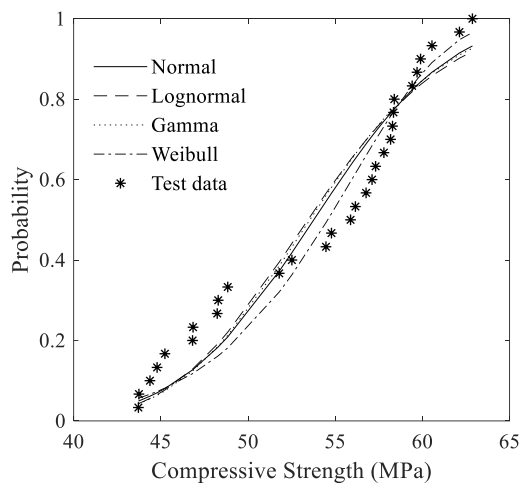

(e) $20 \% \mathrm{SF}$

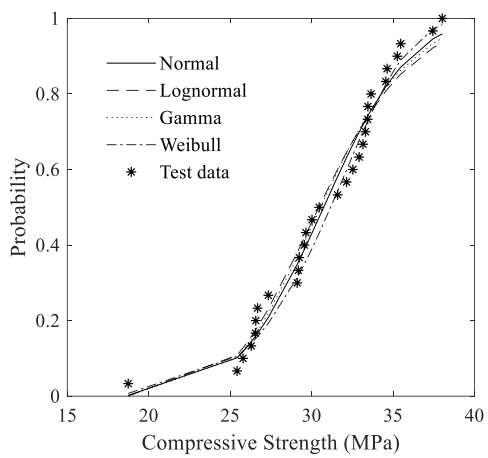

(b) $5 \% \mathrm{SF}$

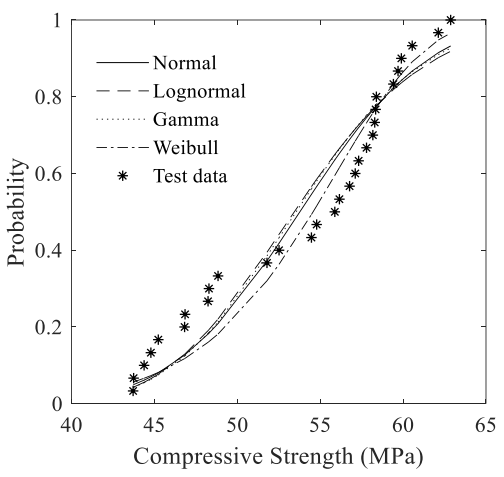

(d) $15 \% \mathrm{SF}$

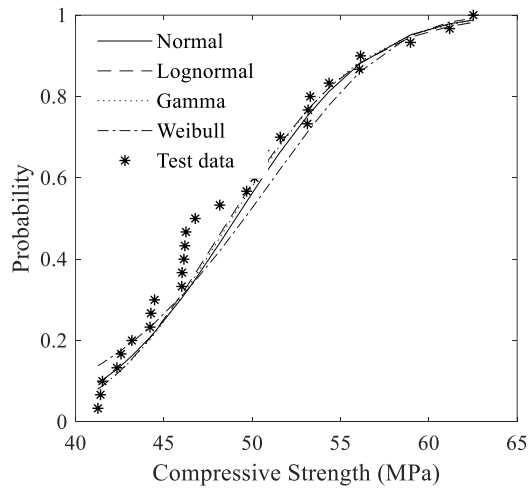

(f) $25 \% \mathrm{SF}$ 


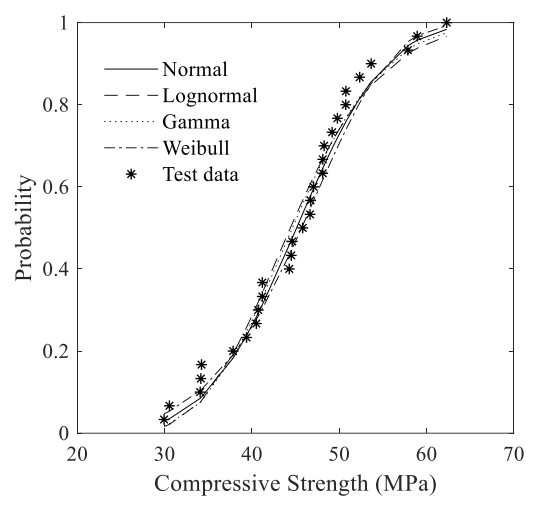

(g) $30 \% \mathrm{SF}$

Fig. 4. Experimental and Cumulative probability distributions for compressive strength (Conversion factor $\mathrm{MPa}=$ multiply by $0.1450 \mathrm{ksi}$ ) 


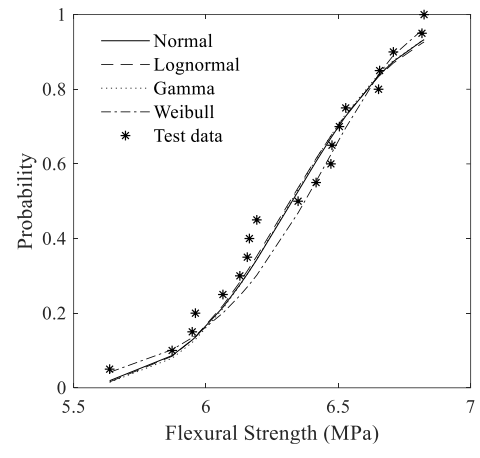

(a) Control

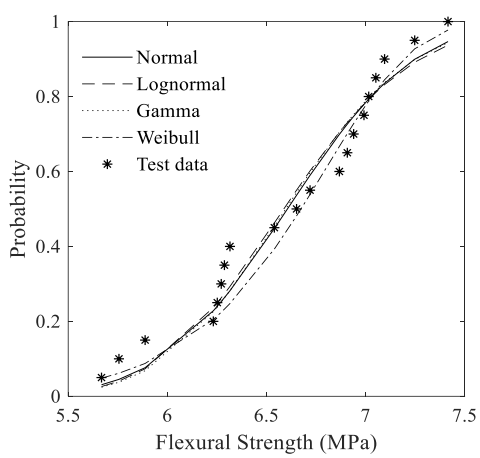

(c) $10 \% \mathrm{SF}$

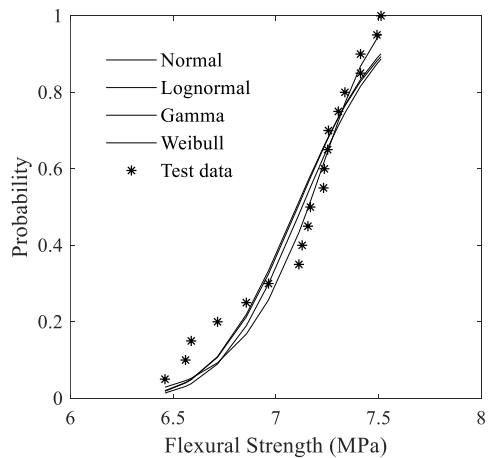

(e) $20 \% \mathrm{SF}$

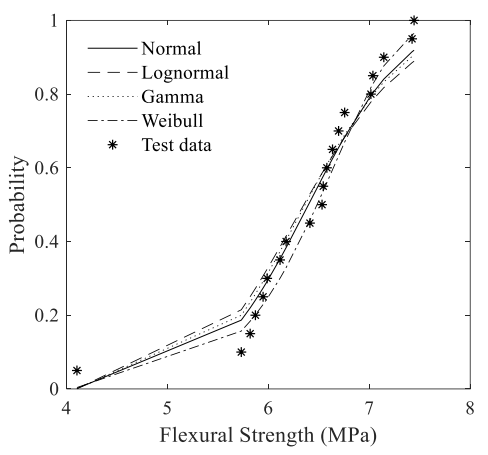

(b) $5 \% \mathrm{SF}$

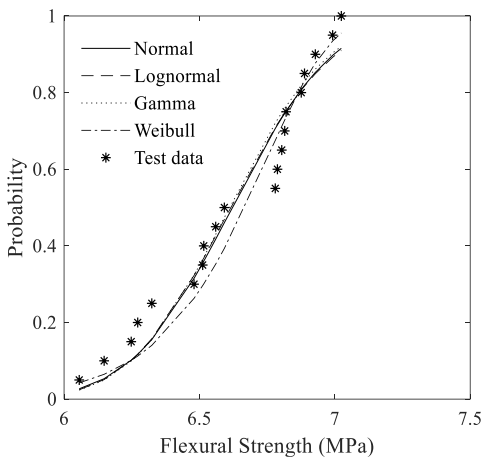

(d) $15 \% \mathrm{SF}$

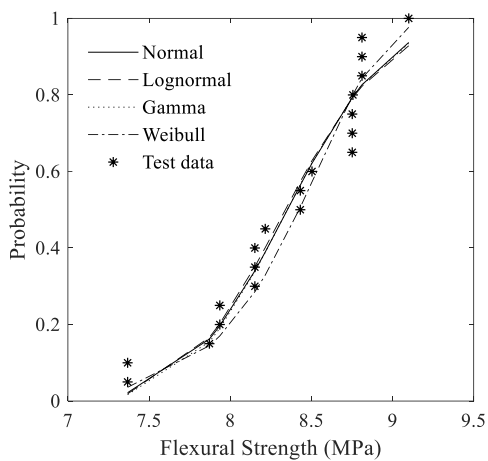

(f) $25 \% \mathrm{SF}$ 


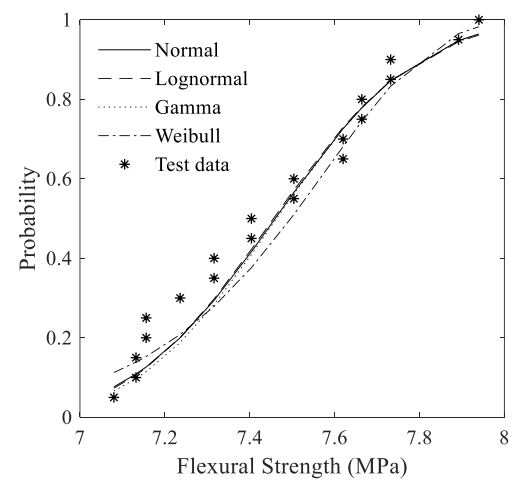

(g) $30 \% \mathrm{SF}$

Fig. 5. Experimental and Cumulative probability distributions for flexural strength (Conversion factor $\mathrm{MPa}=$ multiply by $0.1450 \mathrm{ksi}$ ) 


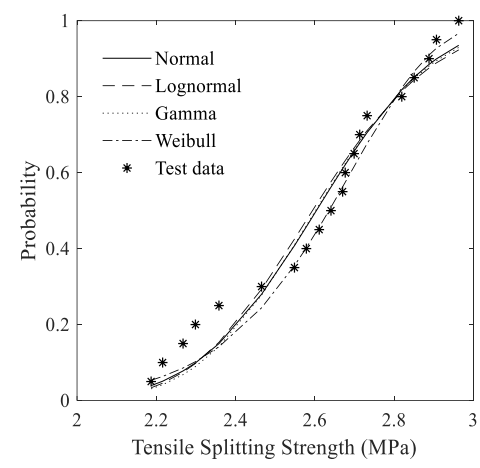

(a) Control

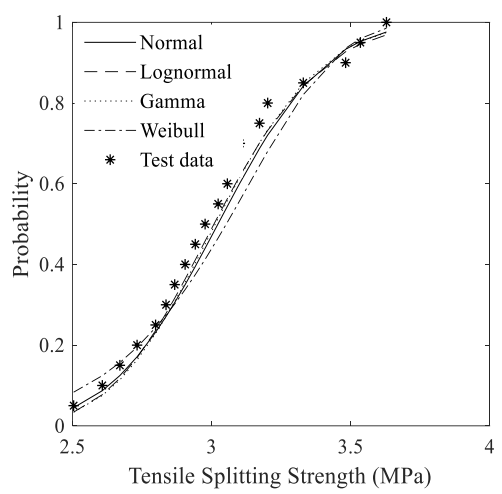

(c) $10 \% \mathrm{SF}$

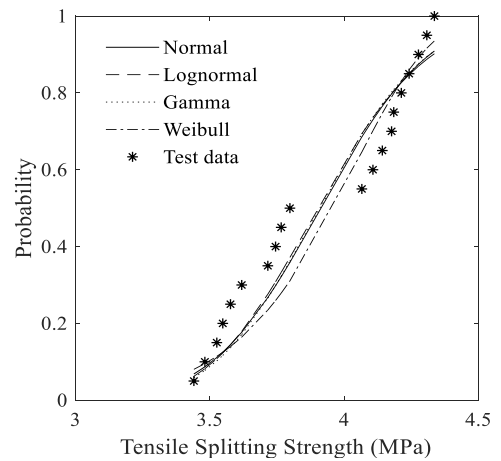

(c) $20 \% \mathrm{SF}$

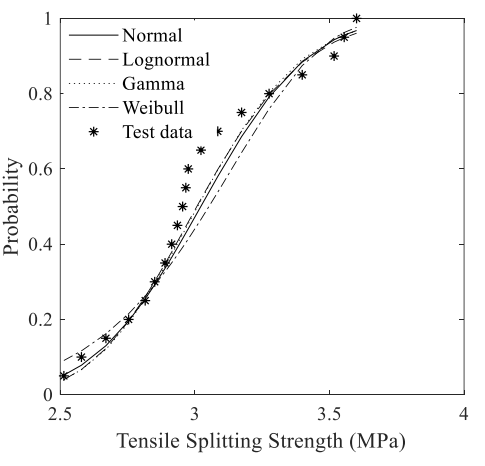

(b) $5 \%$

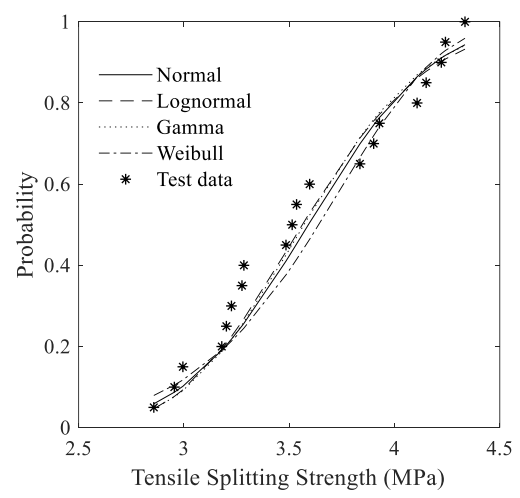

(d) $15 \% \mathrm{SF}$

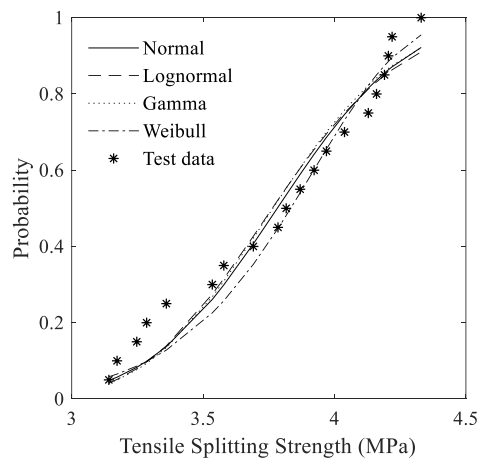

(d) $25 \% \mathrm{SF}$ 


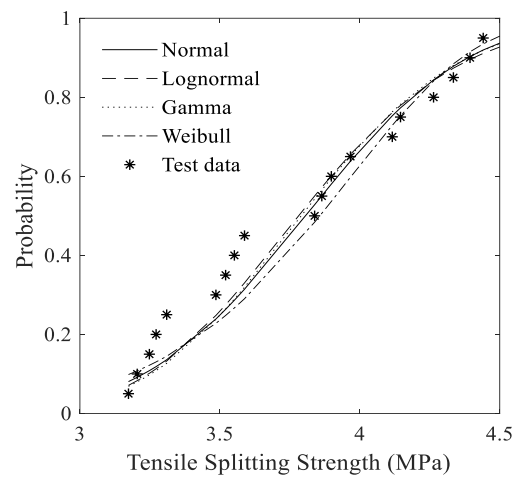

(d) $30 \% \mathrm{SF}$

Fig. 6. Experimental and Cumulative Probability Distributions for Tensile Splitting Strength (Conversion factor $\mathrm{MPa}=$ multiply by $0.1450 \mathrm{ksi}$ ) 


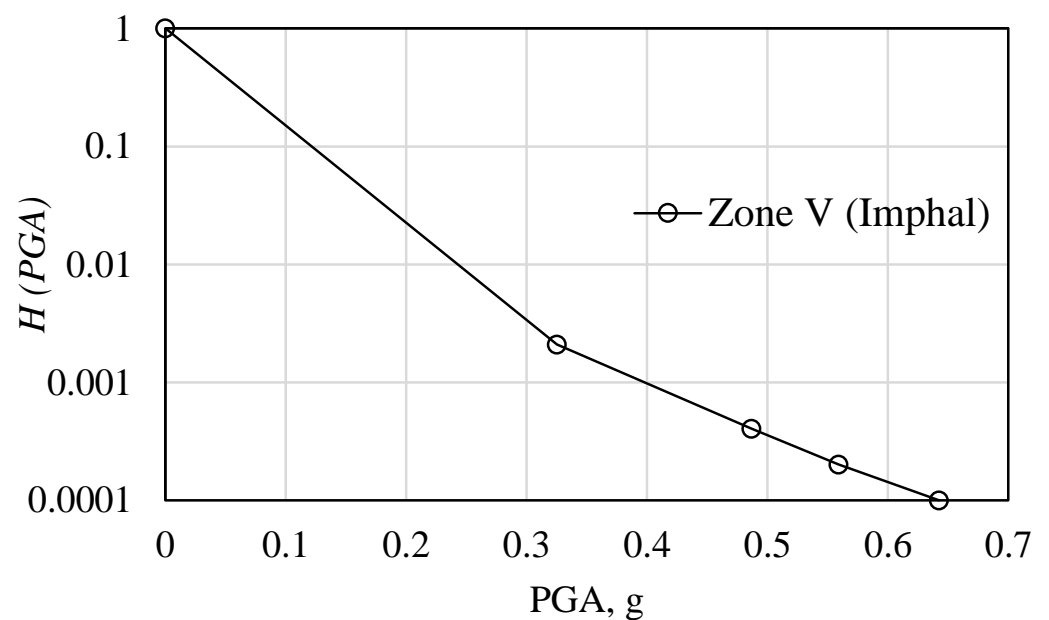

Fig. 7: Selected seismic hazard curves (data from Iyengar et al. 2010) 


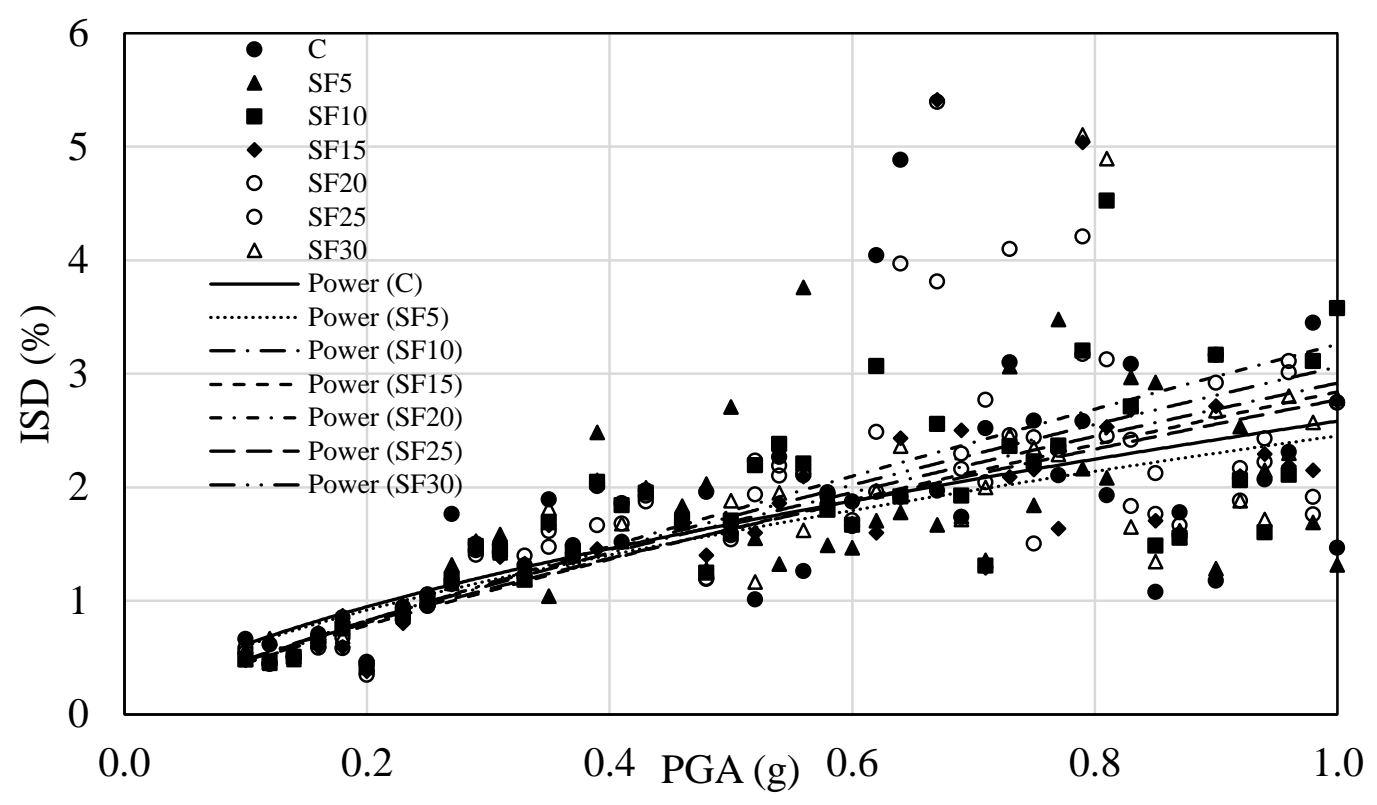

Fig. 9: PSDM models for building frames using SF concrete 


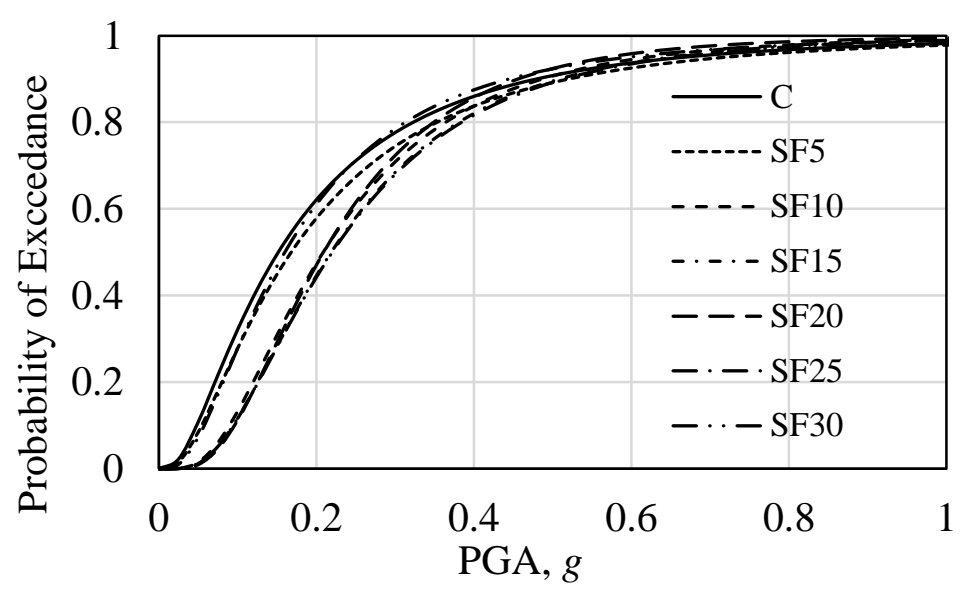

(a) At Significant Damage (SD)

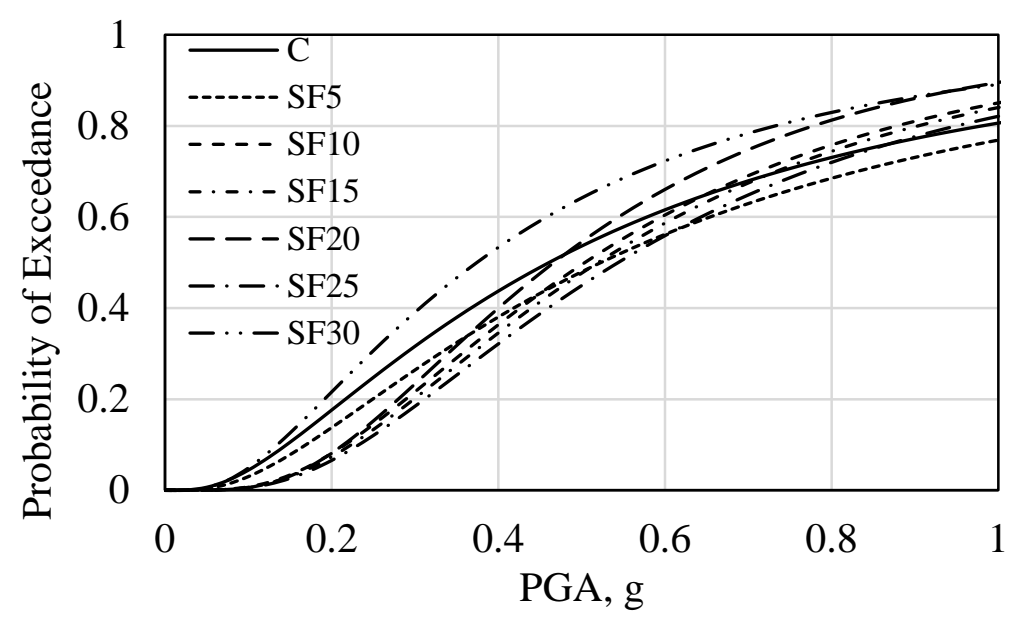

(b) At Collapse Prevention (CP)

Fig. 10: Fragility curves for SF building frames 


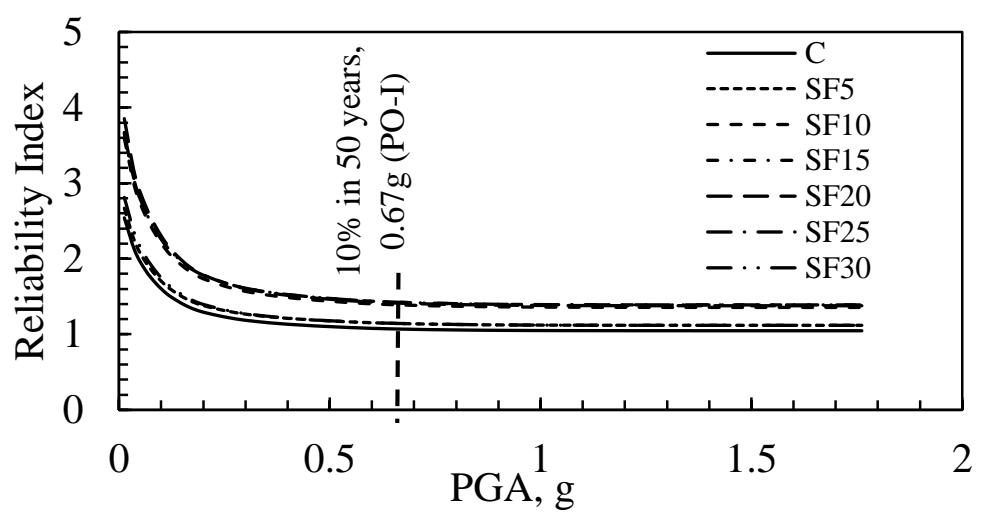

(a) At SD for SF building frames

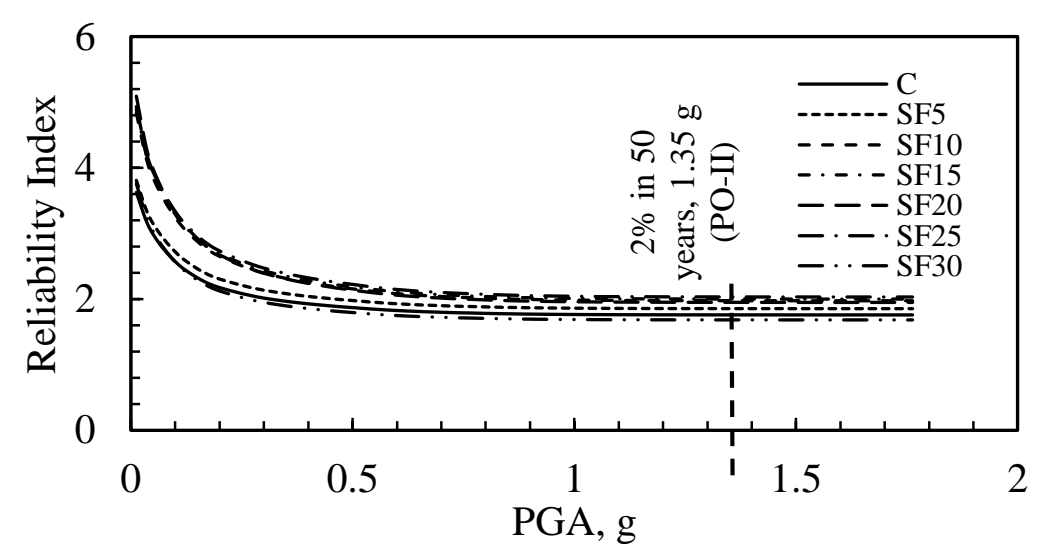

(b) At CP for SF building frames

Fig. 11: Reliability curves for SF building frames 


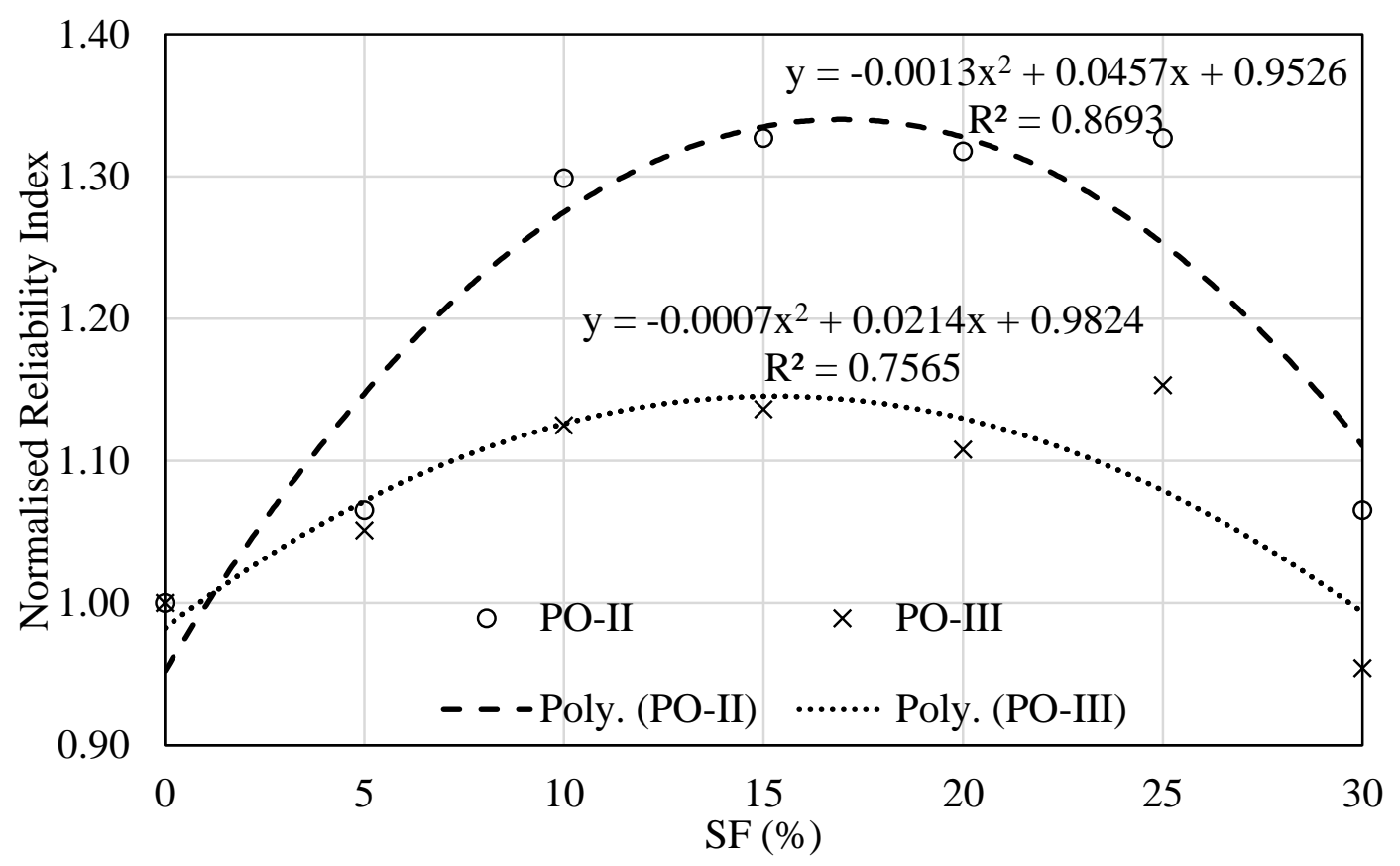

Fig. 12: Percentage of SF versus normalized reliability index 
Fig. 1. Variation of Mean, SD of Compressive Strength (Conversion factor MPa= multiply by $0.1450 \mathrm{ksi}$ )

Fig. 2. Variation of Mean, SD of Flexural Strength (Conversion factor MPa= multiply by $0.1450 \mathrm{ksi}$ )

Fig.3. Variation of Mean, SD of Tensile Strength (Conversion factor MPa= multiply by $0.1450 \mathrm{ksi}$ )

Fig. 4. Experimental and Cumulative probability distributions for compressive strength (Conversion factor $\mathrm{MPa}=$ multiply by $0.1450 \mathrm{ksi})$

Fig 4 (a) Control

Fig 4 (b) 5\% SF

Fig 4 (c) $10 \%$ SF

Fig 4 (d) $15 \%$ SF

Fig 4 (e) $20 \%$ SF

Fig 4 (f) $25 \% \mathrm{SF}$

Fig 4 (g) $30 \%$ SF

Fig. 5. Experimental and Cumulative probability distributions for flexural strength (Conversion factor $\mathrm{MPa}=$ multiply by $0.1450 \mathrm{ksi}$ )

Fig 5 (a) Control

Fig 5 (b) $5 \%$ SF

Fig 5 (c) $10 \%$ SF

Fig 5 (d) $15 \%$ SF

Fig 5 (e) $20 \%$ SF

Fig 5 (f) $25 \% \mathrm{SF}$

Fig 5 (g) $30 \%$ SF

Fig. 6. Experimental and Cumulative Probability Distributions for Tensile Splitting Strength (Conversion factor $\mathrm{MPa}=$ multiply by $0.1450 \mathrm{ksi}$ )

Fig 6 (a) Control

Fig 6 (b) $5 \%$ SF

Fig 6 (c) $10 \%$ SF 
Fig 6 (d) $15 \%$ SF

Fig 6 (e) 20\% SF

Fig 6 (f) $25 \% \mathrm{SF}$

Fig 6 (g) 30\% SF

Fig. 7: Selected seismic hazard curves (data from Iyengar et al. 2010)

Fig. 8: Selected four storey RC frame

Fig. 9: PSDM models for building frames using SF concrete

Fig. 10: Fragility curves for SF building frames

Fig 10 (a) At Significant Damage (SD)

Fig 10 (b) At Collapse Prevention (CP)

Fig. 11: Reliability curves for SF building frames

Fig 11(a) At SD for SF building frames

Fig 11(b) At CP for SF building frames

Fig. 12: Percentage of SF versus normalized reliability index 